\title{
Are unemployment benefits harmful to the stability of working careers? The case of Spain
}

\author{
Yolanda F. Rebollo-Sanz • J. Ignacio García-Pérez
}

Received: 18 March 2014 / Accepted: 17 November 2014 / Published online: 13 December 2014 (C) The Author(s) 2014. This article is published with open access at SpringerLink.com

\begin{abstract}
Unemployment insurance is usually found to show negative effects in the transition from unemployment to a new job. However, the extent to which workers' careers might improve or deteriorate as a result of the unemployment insurance system is not immediately clear. This paper addresses the effects of certain aspects of this system on employment stability by jointly accounting for benefits endogeneity, dynamic selection issues and occurrence dependence. The analysis is undertaken for a dual labour market, such as the market in Spain, where temporary and permanent workers differ with respect to numerous individual and labour market characteristics. We find that non-insured unemployed workers experience a greater rate of transition to employment than insured workers. But we also find that benefits encourage job stability for temporary workers not only by increasing subsequent job tenure but also by increasing the probability of entering into a permanent contract. Finally, we get that shortening the duration of the benefit entitlement period does not seem to lead to significant gains in overall employment stability, which increases at most by $4.3 \%$.
\end{abstract}

Keywords Unemployment insurance $\cdot$ Multivariate mixed proportional hazard model $\cdot$ Job turnover $\cdot$ Employment stability $\cdot$ Employment dynamics

JEL Classification $\quad \mathrm{J} 63 \cdot \mathrm{J} 64 \cdot \mathrm{J} 65 \cdot \mathrm{J} 68$

An earlier version of this paper circulated under the title "Are there gains in employment stability by reducing unemployment benefit entitlement length? The case of Spain".

Y. F. Rebollo-Sanz ( $\varangle)$

Universidad Pablo de Olavide, Crta. Utrera, Km. 1, 41013 Seville, Spain

e-mail: yfrebsan@upo.es

J. I. García-Pérez

Universidad Pablo de Olavide \& FEDEA, Crta. Utrera, Km. 1, 41013 Seville, Spain

e-mail: jigarper@upo.es 


\section{Introduction}

The impact of the unemployment insurance system on labour markets is currently at the heart of political debate (see, for example, OECD 2013). Multiple aspects of the unemployment benefit system are at issue, including the short- and long-term effects of the system and the appropriate balance of efficiency and equity considerations. ${ }^{1}$ In particular, the efficiency properties of unemployment benefits, in terms of employment stability, are theoretically ambiguous. Accordingly, they must be tested empirically.

Empirical research on the effect of benefit duration on the exit rate from unemployment is extensive, both in the US and in Europe. However, empirical literature that describes the effects of the Unemployment Insurance System (UIS, hereafter) on unemployment and employment durations and that controls for selection effects is rather limited due to the scarcity of large micro datasets with complete information on labour market histories.

The main conclusions that can be drawn from the existing literature are that changes to benefit duration produce substantial effects on unemployment duration ${ }^{2}$ and that those benefits tend to be exhausted before individuals return to employment. For example, Meyer (1990) finds that the unemployment exit rate in the US doubles one month before benefits expire. Card and Levine (2000) conclude in the same vein that 13 extra weeks of benefits would raise the average duration of regular claims by approximately one week. The evidence for Europe is rather similar. Roed and Zhang (2003), Van Ours and Vodopivec (2006) and Lalive (2007) all find that benefits strongly affect the duration of unemployment. Furthermore, they also find a large spike in the re-employment hazard at the point of UI exhaustion for job seekers. More close to our empirical strategy, Boone and Van Ours (2009) report that the job-finding rate for permanent jobs in the month of benefit expiration is about three times as high for males and 3.7 times as high for females than it is in months without benefit exhaustion. In the case of transitions to temporary contracts, they find spikes that are approximately $50 \%$ (males) and $75 \%$ (females) higher than regular job-finding rates. Some previous empirical papers have estimated the exhaustion effect of benefits for Spain, being (Bover et al. 2002) the first to quantitatively measure the effect of receiving unemployment benefits on the exit from unemployment. Arranz and Muro (2004) show that, for UI recipients, the hazard rate rises dramatically $-170 \%$ two months prior to exhaustion-, when UI benefits lapse approaches. Alba-Ramirez et al. (2007) investigate benefit recipients' exits from unemployment but they do not analyse the probability of exiting unemployment near the time that benefits expire. More recently, Rebollo-Sanz (2012) differentiates between recalls and entry into new jobs and get that the spike in the unemployment hazard rate at benefit exhaustion differs between recalls and new job entries.

\footnotetext{
${ }^{1}$ Blanchard et al. (2013) recognize that some employment and unemployment protection is desirable and emphasize that although reallocation is important for productivity growth, "much productivity growth also comes from stable employment relationships".

2 See Caliendo et al. (2009) and Tatsiramos and Van Ours (2012) for recent summaries of the main results in this respect.
} 
Hence, there is almost no doubt that lengthier benefit periods favour longer episodes of unemployment. However, the impact of unemployment benefits on the duration of subsequent employment is more scarce and mixed. On the one hand, it is found that the length of the benefit entitlement period is positively correlated with the duration of unemployment, which might decrease subsequent job duration (i.e., the unemployment 'scarring' or 'signalling' effect). ${ }^{3}$ On the other hand, previously insured workers might have lengthier subsequent employment spells because benefits finance the search for good (and therefore durable) matches. Given these competing effects, the overall impact of benefits on employment stability is not obvious. In this sense, Tatsiramos (2009) find that the effect of benefits on employment stability is more pronounced in countries with relatively more generous benefit systems, such as Denmark, Germany, France and Spain, than in countries like Greece and Italy, in which the UI system is underdeveloped. Finally, Caliendo et al. (2012) find that the overall effect of extended benefit duration on exit rates from subsequent employment is negative, but small, and not significantly different than zero.

In any case, however, the literature on these issues takes a short-term perspective and focuses on the effect of unemployment benefits on the duration of single employment and unemployment episodes. However, a medium-term perspective is also highly relevant, as medium- and long-term impacts of the benefit system can differ markedly from the short-term impact if current employment duration depends on previous labour market history. Our paper try to shed light on these issues by proposing an analysis of the effects of benefit entitlement duration on job turnover and workers' labour market stability, taking into account the endogeneity of benefits, dynamic selection and occurrence dependence issues.

This paper also contributes to the empirical literature by analysing the potential interaction of the benefit system with a segmented labour market characterised by two types of workers: stable and unstable. In this regard, we make our assessment for Spain given that its extremely dual labour market responds differently to economic shocks than labour markets in other European economies (see Bentolila et al. 2010). In particular, we wonder whether the UIS might favour stable labour markets paths, not only through the pure matching effect (i.e., by increasing job match quality by allowing individuals to wait for better job offers) but also by favouring the transition from unstable to stable jobs. The alternative to be empirically tested is whether this system is effectively trapping workers in a vicious cycle of unemployment and unstable jobs. $^{4}$

Our empirical analysis is based on duration models and is closely related to the timing-of-events approach developed in Abbring and van den Berg (2004). Formally, the model has two states: employment and unemployment. We model each state follow-

\footnotetext{
3 Evidence from Canada (Belzil 2001) and the US (Centeno 2004) suggests that jobs accepted close to benefit termination have a higher dissolution rate, whereas higher benefit levels increase the quality of job matches, as measured by the duration of employment. On the contrary, Card et al. (2007) and Van Ours and Vodopivec (2008) both find that extended benefits do not affect the "match quality" of subsequent jobs as measured by job duration.

4 In this sense, we aim to address the current literature discussing the consequences of temporary work on individual labour careers-initiated by Booth et al. (2002), by considering the interactions between unemployment benefits and types of job contracts.
} 

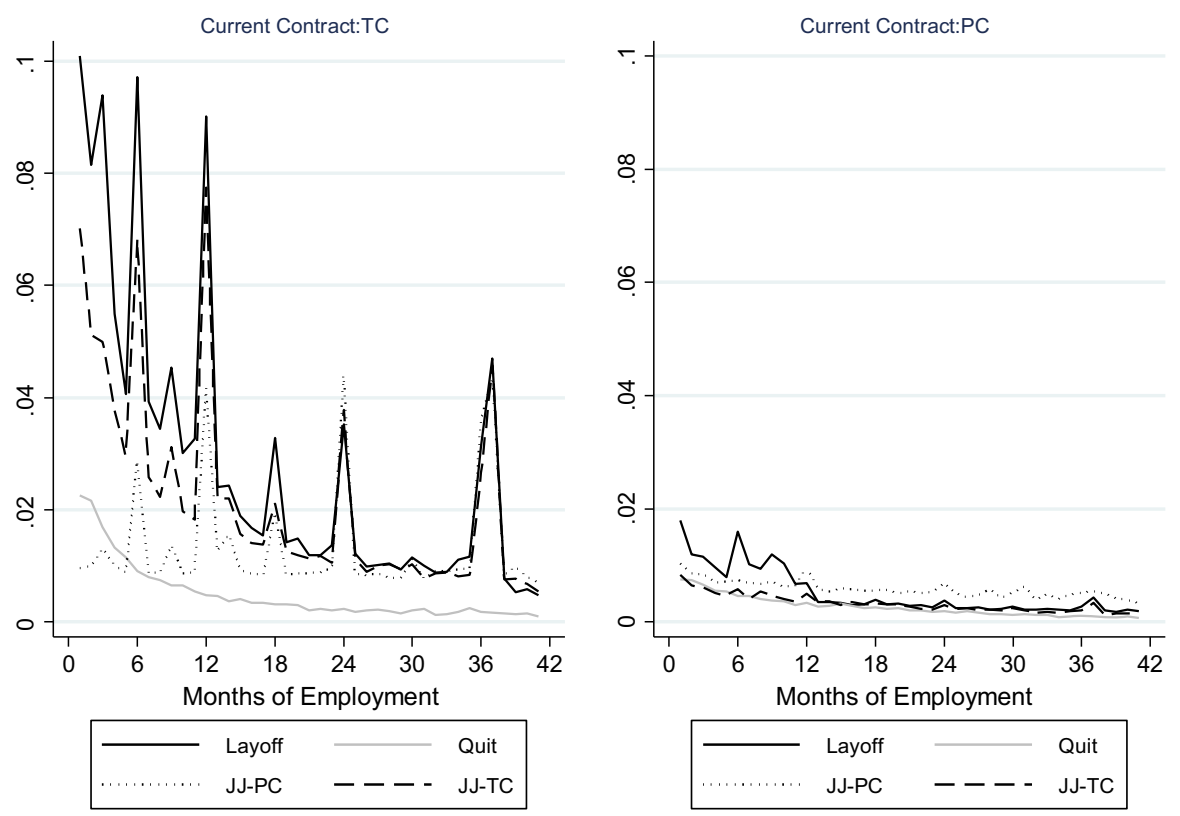

Fig. 1 Empirical employment hazard rates (1995-2007)

ing a competing risk approach to consider the potential endogeneity of each transition and its relation to unemployment insurance benefit parameters. For the employment equation, as illustrated in Fig. 1, we separately model layoffs, quits, job-to-job transitions into unstable or fixed-term contracts and job-to-job transitions into stable or open-ended contracts. Similarly, for the unemployment equation (see Fig. 2), we separately model exits into jobs with fixed-term contracts and exits into jobs with openended contracts. Additionally, our model accounts for the heterogeneous effects of the benefit system based on contract type since we interact our benefit system covariates with the type of contract held by the worker. Differentiating by the type of contract offers a new dimension to the analysis that is crucial to understanding the interaction between the benefit system and dual labour markets, ${ }^{5}$ particularly because the arrival rate of job offers and job duration in this type of labour market vary substantially based on previous and current contract types.

Given the design of the Spanish UIS, all employees who involuntarily become unemployed are entitled to Unemployment Benefits, provided that they have been employed for at least 12 months over the previous 72-month period. Individuals who receive full-time disability benefits, people who leave their jobs voluntarily and any-

\footnotetext{
5 See Güell and Petrongolo (2007) or Rebollo-Sanz (2011) for recent empirical evidence related to the role of temporary contracts as a stepping stone in Spain. Both papers show that the predominance of temporary contracts accounts for the majority of employment-unemployment transitions, and that although most workers are initially hired with fixed-term contracts, some of these workers ultimately become permanent employees.
} 


\section{Empirical Unemployment hazard Rates}
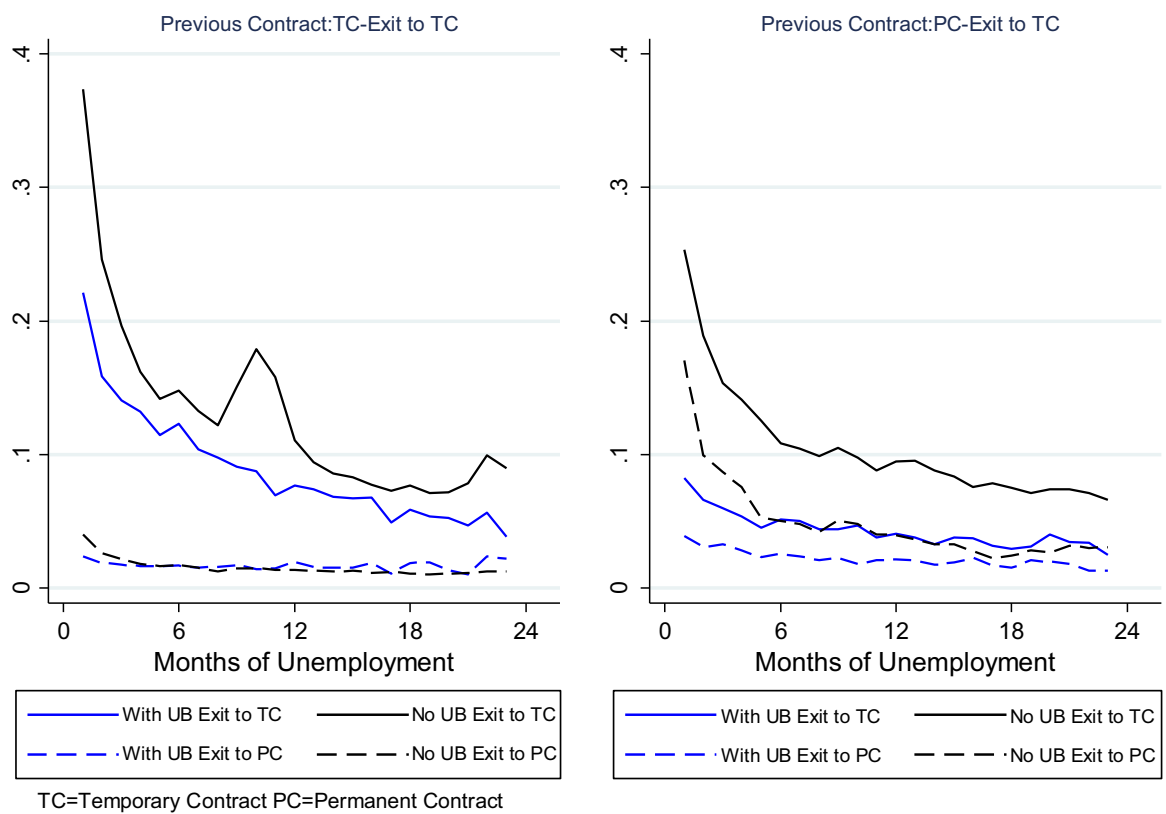

Fig. 2 Empirical unemployment hazard rates for UIS receivers and non-receivers (1995-2007)

one over the age of 64 are excluded from these benefits. Benefits end when individuals cease to be unemployed or reach the maximum entitlement period. During the analysed period, the amount of income provided to each unemployed individual is determined by multiplying the gross replacement rate by the individual's average basic pay over the twelve months preceding unemployment. This replacement rate is $70 \%$ of previous wages for the first six months and $60 \%$ of previous wages from the seventh month onward. ${ }^{6}$ The length of the benefit entitlement period depends on previous employment duration. Specifically, the initial benefit period is at least 4 months, which may be extended in 2-month increments up to a maximum of 2 years, depending on the worker's employment record. Finally, Unemployment Assistance benefits are available for people who have not been working long enough to qualify for the previously described unemployment benefits and for people who have exhausted them and have family responsibilities.

In this paper, we use the information provided by a Spanish administrative database extracted from Social Security records. The analysis will focus on labour market transitions during 1995-2007 for a sample of male workers. We made this decision because, in this time span, ${ }^{7}$ the arrival rate of job offers is more likely to be close

\footnotetext{
6 Today, the benefit recipient receives $50 \%$ of previous income from the seventh month onward.

7 Employment, however, fluctuated quite substantially during this period. According to the Labour Force Survey, the employment growth rate for workers in our sample had two minimum values (below $1.5 \%$ ), in 1996 and 2002, and two maximum values (above 4.3\%), in 1999 and 2006.
} 
to one (or, at least, very large for temporary job offers). Hence, in terms of exits from unemployment, we can better interpret our results as depending primarily on reservation and offered wages. The major recession of 2008-2012 was the most severe recession in developed countries since World War II, and we think it deserves special analysis. ${ }^{8}$

As summarized above, the previous empirical evidence on post-unemployment outcomes suggests that, on average, there is no effect of unemployment benefits on the quality of the post-unemployment job. However, there is some evidence of heterogeneous effects, which lead to zero net effects when this heterogeneity is ignored and which indicate that some individuals might be facing liquidity constraints. Except for Tatsiramos (2009), the existing literature bases its analysis on reforms which is a good identification strategy but it is an alternative not possible in our case. Nevertheless, these papers only look at post-unemployment job characteristics and do not take into account "dynamic" effects as the ones considered in this paper. This is, from our point of view, the main advantage of our approach, which enhance us in order to look for the medium or long-term impact of unemployment benefits on workers' labour market careers. Furthermore, this paper extends the existing literature by analysing the effect of UIS on labour market transitions when the following factors are considered separately: quits, layoffs, and job-to-job transitions as the means of exiting employment, and whether exits from unemployment are to temporary or permanent contracts. Thus, it takes into account a major singularity of the Spanish labour market, i.e., strong segmentation due to the existence of temporary and permanent contracts and the high job-turnover rate.

In accordance with previous literature, particularly with the results in Boone and Van Ours (2009), our findings show that non-insured unemployed workers experience a greater rate of transition to employment than insured workers, except at the time of benefit expiration. Incidentally, we find that benefits encourage job stability for temporary workers not only by increasing subsequent job tenure - the pure matching effect - but also by increasing the probability of entering into a permanent contract. Finally, our simulation exercises demonstrate that reducing (or increasing) the benefit entitlement period does not lead to substantial changes in employment stability because, although unemployment duration is being affected in the predicted direction, job turnover also increases (decreases) when unemployment benefits are cut (raised), especially for temporary workers. In sum, job stability hardly varies both when reducing or increasing benefit entitlements, being this result quite novel in the literature. ${ }^{9} \mathrm{We}$ show that the reason for this is because the effects on the overall time spent employed and on job turnover tend to cancel each other out making total time employed, our measure of job stability, almost unchanged under any of the two alternative measures. On

\footnotetext{
8 There is empirical literature that points out that the effect of the unemployment insurance system might strongly differ along the business cycle. For instance, Schmieder et al. (2012) show that the moral hazard effect of unemployment insurance benefits is significantly lower in recessions than in booms.

9 As explained above, the papers that analyses these issues for the Spanish labour market focus on the estimation of the direct impact of unemployment benefits on the exit for unemployment. The few studies that deal with employment stability only deal with short-term impacts and estimate them with no connection to the one on unemployment exit rates.
} 
the contrary, when we simulate a situation where the transition to permanent contracts is more likely, the long-term impact on job stability is much larger. This illustrates that, in terms of enhancing job stability, it might be more important to cope with the strong dual character of the Spanish labour market than to reshape the UI system.

Our paper starts with a brief description of the data we use and main characteristics of the sample. Section 3 describes our empirical model, and Sects. 4 and 5 provide our main results. The last section presents our basic conclusions.

\section{Data and descriptive statistics}

We work with an event history data set that comes from Spanish Social Security records (Longitudinal Working Lives Sample, LWLS). ${ }^{10}$ The LWLS, which is compiled annually, comprises a sample of over one million worker case histories. The initial database includes all individuals who came into contact with the Social Security system-either as an employee or an unemployed benefit recipient-at least once between 2005 and 2012. This database provides highly detailed information about workers' past and present labour activities, including contract type, receipt of UIS benefits, and reasons for job termination. Individual characteristics, such as age and nationality, are also present in the database.

We consider two labour market statuses: employed ${ }^{11}$ and unemployed. The duration of each job spell is based on the start and end dates specified in the contract as provided by the dataset. Likewise, we compute the duration of each unemployment episode by measuring the time lapse between the end date of the worker's previous contract and the start date of the new one. The unemployment state includes registered unemployment with or without receiving benefits, and we control whether it is due to a layoff or a quit. For the purpose of this paper, it is interesting to emphasise that, with our database, we can compute not only the period of unemployment during which workers are covered by UIS (either contribution-based or assistance benefits) but also the period after benefits expire. This contrasts with other administrative datasets, in which the unemployment period is truncated at the point benefits expire. ${ }^{12}$

We track each spell to the point of transition or to the end of the observation period. In the case of employment spells, each uncensored job spell is identified as either a layoff, a quit, a job-to-job transition to a permanent contract (hereafter JJPC) or a job-to-job transition to a temporary contract (hereafter JJ-TC). ${ }^{13}$ We include transitions with an observed unemployment spell of 15 days or less within job-to-job transitions. To avoid odd behaviour in the estimated baseline hazard functions due to the scarcity of observations spanning longer durations, we right-censored any observed

\footnotetext{
10 For a detailed description of this sample, see Duran (2007) and García Pérez (2008).

11 We exclude from the sample self-employed workers because they are not entitled to receive unemployment benefits.

12 Indeed, Card et al. (2007) posit that the effect of potential benefits duration on the unemployment exit rate is conditional on the way the researcher measures the end-of-benefit spike phenomenon. We offer an illustration of this result by using our estimation sample at the end of Sect. 6.

13 Employment spells shorter than a month are not considered in the analysis.
} 
spells of unemployment longer than or equal to 36 months and any observed spell of employment longer than or equal to 120 months.

The sample selection criteria are designed to minimise the impact of the initial conditions problem on the econometric analysis. In particular, we select individuals whose first observation in the dataset corresponds to their first employment spell. Thus, we limit the sample to workers who are between the ages of 16 and 26 years when they start this first job. After the first observation, we follow each worker over time. Hence, we can compile an individual's UIS claim history at any point in time, provided we have all of the information regarding his labour market career. For example, we compute UIS entitlement duration for each individual by combining the information on his previous and current employment duration with information on his previous unemployment duration, if any (with or without benefits), according to the rules laid out in the Spanish UIS System. The database includes the date of the last UIS claim, thereby enabling us to determine the number of weeks of insured unemployment that have already accumulated at the start of a new employment spell. It is important to stress that the administrative source and the comprehensive nature of the dataset reduce measurement errors of these two parameters to a negligible level.

The final data used in this analysis cover the working careers of a sample of male Spanish workers aged 18-55 years over the period 1995-2007. ${ }^{14}$ We select this period of analysis because the favourable macroeconomic context during these years favoured job creation. That is, the arrival rate of job offers during this period can be assumed to be close to one (or, at least, very large for temporary job offers), ${ }^{15}$ which enables us to better interpret the results of the duration model presented in the paper.

Tables 1 and 2 provide a descriptive overview of the main sample characteristics and events recorded in our dataset, with the sample split according to labour market status: employment and unemployment. First, the data reveal a large degree of job turnover during the sample timeframe. Although average employment duration is 21 months, the median contract duration is 6 months, and $25 \%$ of employment spells last 2 months or less. Average unemployment duration is 6.5 months, and median unemployment duration is 3 months. The average number of employment and unemployment spells during the analysed period is 4.27 and 2.23, respectively. Finally, the average share of time spent employed over the total timeframe is $71 \%$. Note, however, that this ratio drops to $27 \%$ for one out of every four workers in the sample. The large divergence between the mean and the median shows that there are individuals in the sample with a large degree of job mobility; that is, with below-average durations of both unemployment and employment spells. The existence of this group of workers suggests the possibility of substantial unobserved heterogeneity, perhaps correlated across spells and states, which affects selection into employment and unemployment. Such sample selection may induce some correlation of the unobserved heterogeneity component

\footnotetext{
14 We only consider male workers because the professional careers of female workers are more often interrupted due to inactivity reasons, such as maternity leave and childcare, which are not always well identified in the dataset.

15 Silva and Vázquez-Grenno (2013) study the dynamics of the Spanish Labour Market for the period 1987-2010 and determine that although the separation rate drives unemployment during recessions, the job-finding rate acquires greater relevance in expansionary periods.
} 
Table 1 Main characteristics of the sample of workers (1995-2007)

\begin{tabular}{llll}
\hline & Mean & Median & P25 \\
\hline Contract duration & 21.19 & 6 & 2 \\
Duration of unemployment & 6.55 & 3 & 1 \\
$\quad$ Number of employment & 4.27 & 3 & 1 \\
$\quad$ spells & 2.23 & 1 & 0 \\
$\quad$ Number of unemployment & & $62 \%$ & $27 \%$ \\
$\quad$ spells & $71 \%$ & & \\
$\quad$ Share of time spent employed & & & \\
$\quad$ Sample size (workers) & 193,797 & & \\
\hline
\end{tabular}

Mean and median duration in months

Table 2 Overview of recorded events/outcomes (1995-2007)

\begin{tabular}{llc}
\hline & Transitions & $\begin{array}{c}\text { Average spell } \\
\text { duration }\end{array}$ \\
\hline Employment spells & & \\
Censored employment spells & $22.93 \%$ & 49.60 \\
Layoffs & $34.90 \%$ & 7.18 \\
Quits & $10.37 \%$ & 7.58 \\
Job-to-job to a PC & $11.54 \%$ & 15.13 \\
Job-to-job to a TC & $20.26 \%$ & 8.33 \\
Sample size (spells) & $1,262,004$ & \\
Unemployment spells & & 6.05 \\
Censored & $6.81 \%$ & 5.92 \\
Exit to TC & $91.40 \%$ & 12.59 \\
Exit to PC & $1.80 \%$ & \\
Sample size (spells) & 311,699 & \\
\hline
\end{tabular}

$T C$ temporary contract,

$P C$ permanent contract

with the UIS System variables because eligibility rules make such variables dependant on workers' labour market histories. This issue will be addressed in the econometric analysis.

Table 2 offers an overview of the recorded events. The data reveal that layoff is the most common employment exit alternative for this sample of workers; indeed, $34.9 \%$ of employment spells end for this reason. It is also worth noting that mean employment duration is the shortest for this type of employment transition (7.1 months). In comparison, mean employment duration is the longest for JJ-PC transitions (15.1 months). Turning our attention to the sample of unemployed workers, we can observe that the most common exit is to a job holding a temporary contract $(91 \%)$, whereas the exit to a permanent contract is much less frequent $(1.8 \%)$. 
Table 3 Mean observed employment duration (months)

\begin{tabular}{lll}
\hline Entry from & Current contract & \\
\cline { 2 - 3 } & TC & PC \\
\hline Unemployment (without UIS) & 10.22 & 34.09 \\
Insured unemployment & 13.00 & 37.83 \\
Months of entitlement & & 35.53 \\
4 & 11.19 & 38.52 \\
$5-8$ & 12.80 & 43.34 \\
$9-12$ & 14.90 & 38.62 \\
$13-18$ & 15.61 & 35.21 \\
$>18$ & 14.17 & 40.75 \\
Job-to-job & 14.97 & \\
\hline
\end{tabular}

$T C$ temporary contract,

$P C$ permanent contract

2.1 Interactions between the UIS system and labour market paths: some stylised facts

In this paper, we are primarily interested in the effects of benefit entitlement duration on individuals' employment stability. Because both unemployment and employment duration might be correlated with the duration of unemployment benefits, the following subsections provide a review of the different effects that might be relevant to the assessment of this issue.

\subsubsection{The matching effect}

We start by looking at whether benefit duration is positively correlated with subsequent employment duration. In this paper, we consider job duration to be a measure of job match quality. ${ }^{16}$ Table 3 presents mean employment duration for three alternative job-entry paths: (1) job-to-job transition; (2) insured unemployment spell; and (3) uninsured unemployment spell. The data in this table show that job-to-job transitions tend to be the transitions with the lengthiest subsequent job spells, followed by benefit receivers. For the latter group, job duration increases with the length of the benefit period. Although the focus of our analysis is on the relationship between UIS and subsequent employment stability as an indicator of a good match, we will also analyse the influence of benefits on the type of transition experienced. In particular, our data show that employees who receive benefits have a greater chance of entering into a new job with a permanent contract than individuals who do not receive benefits. For example, the share of insured workers that hold a permanent contract in their subsequent job is $29 \%$; for uninsured workers, it is just $21 \%$.

\footnotetext{
16 Match quality is difficult to quantify empirically. In this paper, we rely on theory to identify job tenure with match quality. The concept that a lengthy job duration represents a good match comes from Jovanovic (1979), who finds that a match is a pure experience good; i.e., the quality of a match is not known ex ante, but must be experienced. We consider this approximation of match quality especially relevant for highly segmented labour markets like the one in Spain.
} 
Table 4 Unemployment exit probability and the length of the UIS entitlement: (\%)

\begin{tabular}{|c|c|c|c|c|c|c|}
\hline & \multicolumn{6}{|c|}{ Unemployment duration (months) } \\
\hline & \multicolumn{3}{|c|}{ Prev. contract TC } & \multicolumn{3}{|c|}{ Prev. contract PC } \\
\hline & $4(\%)$ & $8(\%)$ & $12(\%)$ & $4(\%)$ & $8(\%)$ & $12(\%)$ \\
\hline \multicolumn{7}{|c|}{ Exit to TC } \\
\hline \multicolumn{7}{|c|}{ UIS entitlement } \\
\hline 4 & 42.33 & 20.45 & 18.54 & 46.15 & 12.42 & 15.38 \\
\hline 8 & 24.95 & 44.77 & 13.92 & 14.69 & 45.83 & 20.83 \\
\hline 12 & 18.77 & 20.16 & 41.88 & 15.42 & 10.53 & 59.65 \\
\hline \multicolumn{7}{|c|}{ Exit to PC } \\
\hline \multicolumn{7}{|c|}{ UIS entitlement } \\
\hline 4 & 0.65 & 0.40 & 0.98 & 2.02 & 0.02 & 0.01 \\
\hline 8 & 0.38 & 0.65 & 0.01 & 0.18 & 1.67 & 0.02 \\
\hline 12 & 0.37 & 0.38 & 0.01 & 0.15 & 0.01 & 0.01 \\
\hline
\end{tabular}

$T C$ temporary contract, $P C$ permanent contract

\subsubsection{The exhaustion effect}

Almost $50 \%$ of our sample of unemployed workers receives unemployment benefits, being this rate much larger among workers previously hired under a permanent contract $(63 \%)$ than among temporary workers (42\%). Table 4 shows unemployment outflows in relation to benefit entitlement duration by the type of contract held in previous and subsequent jobs. Note that this exit probability differs considerably among the different cases considered. In this regard, some salient points should be emphasised. First, the correlation between unemployment duration and entitlement length is substantial and positive. That is, insured workers experience longer periods of unemployment than other workers. Second, the importance of the timing of benefit exhaustion is evident. Specifically, the probability of unemployment exit displays large spikes at the time benefits expire. For example, a temporary contract worker entitled to 4 months of benefits has an unemployment exit probability of $42.33 \%$ at month 4; this probability decreases by more than 20 percentage points once benefits are exhausted. The same pattern is observed for the other UIS entitlement lengths and for workers who previously held a permanent contract.

The statistical analysis presented above provides some interesting insights into the labour market paths of workers and how they can be the related to the Spanish UIS system. ${ }^{17}$ It seems that the duration of both employment and unemployment are related to UIS entitlement length. This empirical evidence will be considered in our econometric model to evaluate the relationship between the Spanish UIS and individuals' labour market stability.

\footnotetext{
17 In Rebollo-Sanz (2012) one can also find empirical evidence of the importance of the eligibilityrequirement effect to employment outflows.
} 


\section{Methodology}

To investigate whether the UIS affects job stability, it is crucial to account for dynamic selection and endogeneity issues (i.e., the endogeneity of previous unemployment duration on subsequent employment duration). For this purpose, we use duration models that are closely related to the timing-of-events approach of Abbring and van den Berg (2004). This approach is able to solve the endogeneity problem caused by selective treatment by exploiting the variation in the timing of each transition. In particular, we set up a multivariate mixed proportional hazard rate model (MMPH) that combines information related to an individual's use of the UIS system with information on employment and unemployment dynamics.

Our evaluation setup requires us to address the issue of multiple selectivity. As a basis of the analysis, we model the event history of an individual starting with his first entry into the state of employment $\left\{\mathrm{T}_{e}\right\}$. The first selection relevant to our study is the individual's exit from the current employment spell and, in particular, how the design of UIS might influence the type of exit (layoff, quit, JJ-TC, JJ-PC). The duration of the employment spell $\left\{\mathrm{T}_{\mathrm{e}}\right\}$ will be affected by the "matching effect"; that is, lengthier UIS durations might help to find the right "match" and thereby guarantee job stability or, at least, it may favour lengthier employment spells, either by reducing the layoff probability or by increasing job-to-job transitions to permanent contracts. Based on the descriptive analysis previously presented, one could infer that this effect should be particularly relevant for workers who start with a temporary contract and obtain a permanent one after a spell of unemployment. Note that because the exit from employment to each competing risk is driven by observed and unobserved characteristics and therefore by a non-random process, the composition of the subsample of job seekers with respect to observables and non-observables is different than the subsample of job-to-job movers.

Once the individual is unemployed $\left\{\mathrm{T}_{u}\right\}$, the second selection process takes place. The unemployed worker can re-enter employment when he receives a job offer and accepts it. In Spain, the offer arrival rate for jobs with permanent contracts is notably lower than the rate for jobs with temporary contracts. Accordingly, although the design of UIS might influence the timing and the type of exit we have two competing effects in this case. Specifically, lengthier benefit entitlement periods lead to longer unemployment spells, which may negatively affect the arrival rate and types of job offers the individual receives (due to the depreciation of general human capital skills, negative signalling, etc.). However, the longer the benefit entitlement period and corresponding lengthier unemployment spell might give the worker adequate time to search for and find a good and durable job offer (i.e., employment with a permanent contract). Hence, there is a selection process wherein the composition of the subsample of job seekers (with respect to observables and non-observables) is different than the subsample of new job entrants.

Handling the selection problems outlined above requires the control of observable and unobservable individual differences and an allowance for the correlation between different unemployment spells and employment processes. This is accomplished by the simultaneous estimation of employment and unemployment spells with correlated unobservable characteristics. The non-random selection process due to observed 
characteristics is controlled by the inclusion of covariates that comprise current and past individual and job characteristics. To account for selectivity in the level of unobserved characteristics, we specify unobserved heterogeneity specific to each transition, thereby allowing for correlation between the different states of the individual's history due to his time-invariant unobserved characteristics.

By combining such a design with our precise data, the effect of interest can be separated from selectivity issues. Assuming for reasons of tractability and interpretation that the hazard rates follow the proportionality assumption and are set in discrete time, we have that the proportional hazard assumption ${ }^{18}$ implies that each hazard takes the complementary log-log form (Jenkins 1995) $\left\{h_{k}^{s}(j / \Omega)\right\}$, where the index $s$ denotes the type of spell ( $s=e, u$, that is, employment or unemployment), the index $k$ denotes the type of transition that is specific to each state $s$ (4 for the employment state and $k_{u}=2$ for the unemployment state), and the index $j$ denotes time along the corresponding spell. Expanding this using the parameters involved in our analysis gives:

$$
h_{k}^{s}(j / \Omega)=1-\exp \left(-\exp \left(\left(U I S^{s} * C^{s}\right) \rho_{k}^{s}+l h^{s} \gamma_{k}^{s}+x^{s} \beta_{k}^{s}+d \delta_{k}^{s}+v_{k}^{s}\right) \lambda_{k}^{s}\right)
$$

We define six sets of explanatory variables: UIS contains the individual economic incentives embedded in the UIS System, all of which interact with the type of contract (C); $l \mathrm{~h}$ consists of several variables that control for occurrence dependence issues, including the number of previous unemployment spells and employment spells holding a permanent contract; $x$ is based on observed individual and job control variables, including, but not limited to, age, nationality, part-time jobs, employment by a temporary work agency, type of contract, sector of activity, firm size, job qualification and firm ownership structure; $d$ contains variables to control for aggregate and regional demand side effects, including the quarterly regional unemployment rate and the quarterly GDP growth rate; $\lambda$ is the integrated baseline hazard; and, finally, $v_{k}^{s}$, covers unobserved individual characteristics, assumed to be specific to the origin and destination states. ${ }^{19}$

Although, we apply a proportional hazard rate model, we emphasise that nonparametric identification does not rely on the proportionality assumption. Additional sources of identification include the existence of repeated employment and unemployment spells (Abbring and van den Berg 2004) and, more importantly, the abundance of exogenous time-varying covariates ${ }^{20}$ (Eberwein et al. 2002; Brinch 2000; Gaure et al. 2007).

\footnotetext{
18 The model is proportional in the sense that unobserved and most observed characteristics are assumed to affect individual hazard rates multiplicatively.

19 That is, all five hazard rates are tied together through the joint distribution of unobserved heterogeneity. The estimated correlation between unemployment duration and subsequent employment duration through the UIS system could be spurious if individual unobserved heterogeneity affecting unemployment duration is correlated with the unobserved heterogeneity affecting job duration.

20 As suggested by Eberwein et al. (2002), time-varying variables naturally provide an exclusion restriction in the sense that past values of these variables affect current outcomes only through the already realized selection process. Hence, they facilitate the disentanglement of causal treatment and duration effects from the impact of unobserved sorting.
} 


\subsection{Parameterisation of the UIS effects}

\subsubsection{The unemployment hazard}

For the unemployment equation, the effect of the UIS entitlement period by type of contract is modelled as follows:

$$
U I S^{u}=\operatorname{Dur} B^{*} \rho_{1}^{u}+E x B^{*} \rho_{2}^{u}+(\operatorname{DurB} * \operatorname{Dur} U)^{*} \rho_{3}^{u}
$$

where, DurB represents the number of insured months left before benefit exhaustion, and $E x B$ is a dummy variable that takes a value of one when the worker exits from unemployment at the time benefits expire, and takes a value of zero otherwise. These variables capture the non-stationary effects inherent in the UIS system. One could claim that a worker's job search effort and/or job acceptance probability increases as the month of benefit exhaustion draws closer. From a firm's perspective, assuming as given this behaviour by the worker, the probability of hiring the worker also increases as the month of benefit exhaustion approaches, with this effect being tougher for workers with a strong attachment to the labour market. The third (DurB*DurU) term of the above expression is an interaction of the unemployment duration with the first variable to allow for the heterogeneous effects of the benefit entitlement across the length of the unemployment spell.

We are able to correctly identify the exhaustion effect with this specification because the sample includes: (1) unemployed workers both with and without UIS; (2) it also includes workers with the same observed unemployment duration but different entitlement durations; (3) but more importantly, we can follow the unemployed workers after their unemployment benefits have expired. ${ }^{21}$ The limited duration of benefits implies that individuals with different entitlement durations should have different optimal paths of reservation wages and search efforts over time. This non-stationarity is the way to identify the effects of UIS entitlement duration on unemployment duration.

Because all UIS parameters interact with the type of contract held by the worker in the previous job, we can evaluate some new ideas based on this model specification. In particular, because benefits offer financial support to keep searching for better job offers, we wonder whether insured workers experience a greater probability of entering into a new job holding a permanent contract as opposed to a temporary contract.

\subsubsection{The employment hazard}

In the employment equation, we model the economic incentives embedded in the UIS system as follows:

$$
U I S^{e}=U\left(\operatorname{Dur} U * \rho_{1}^{e}+\operatorname{Dur} B * \rho_{2}^{e}\right)
$$

\footnotetext{
21 Card et al. (2007) review the literature on the "spike" in unemployment exit rates around benefit exhaustion and show that spikes are typically much smaller when spell length is defined by the time to next job than when it is defined by the time spent on the unemployment system.
} 
The term $U$ is a dummy variable that takes a value of one for workers who had an unemployment spell before the current job and takes a value of zero otherwise. ${ }^{22}$ The covariate DurU represents the duration of the previous unemployment spell, and DurB represents the UIS entitlement length. Hence, this expression shows that the distribution of job duration depends on previous unemployment duration, and this dependence is specified such that the respective effects of benefit entitlement duration and unemployment duration can be distinguished. The idea is to identify any heterogeneous effects of benefits on employment stability for alternative unemployment experiences. In particular, the identification of the matching effect is based on the concept that differences in optimal job search behaviour of unemployed individuals with different entitlement lengths should lead to different realised distributions of subsequent job quality. That is, individuals with a given length of unemployment and the same level of benefits, but a longer period of benefit entitlement, may keep searching and wait for job offers that are better in terms of employment stability.

Like the unemployment equation, all parameters in the employment equation interact with the type of contract held by the employee. Hence, we can measure whether the matching effect differs by contract type and whether benefits (indirectly) favour job stability by increasing the workers' chances of entering into jobs with permanent contracts.

\subsection{The likelihood function}

To estimate this discrete-time duration model, we construct a panel dataset such that the spell length of any given individual determines a vector of binary responses. We define $\delta_{j k_{s}}^{s}$ as a binary indicator variable denoting a transition to potential destinations through an exit to one of the competing alternatives $k$, i.e., $\tau_{j k s}=1$ if individual $i$ transits from $s$ to one of the competing $k_{s}$ alternatives and is zero otherwise. Let $L_{i}$ be the complete set of outcome indicators available for individual $i$ (multiple-spells). The contribution to the likelihood function formed by the event pattern of a particular individual, conditional on the vector of unobserved variables $v_{i}=\left(v_{1}, v_{2}, v_{3}, v_{4}, v_{5}\right)$, can then be formulated as:

$$
L_{i}\left(v_{i}\right)=\prod_{y_{i s k \in Y_{i}}}\left[\prod_{s=1}^{S} \prod_{j=1}^{J} \prod_{k_{s}=1}^{K_{s}}\left(h_{j k_{s}}^{s}\right)^{\tau_{j k_{s}}^{s}}\left(1-h_{j k_{s}}^{s}\right)^{1-\tau_{j k_{s}}^{s}}\right]
$$

We introduce unobserved heterogeneity non-parametrically by means of the nonparametric maximum likelihood estimator (NMPLE). In practice, this implies that the vectors of unobserved attributes specific to each type of transition are jointly discretely distributed. The number of mass points is determined by adding location vectors until it is no longer possible to increase the likelihood function (Heckman and Singer 1984; Gaure et al. 2007). Assuming that unobserved covariates are jointly discretely distributed with $Q$ number of support points, the data likelihood function

\footnotetext{
22 In addition, there is a dummy variable in the empirical model that takes a value of one if the previous unemployment spell was due to a quit instead of a layoff.
} 
can be written as:

$$
L=\prod_{i=1}^{N}\left[\sum_{l=1}^{L} q_{l} L_{i}\left(v_{l}\right)\right] \text {, with } \sum_{l=1}^{L} q_{l}=1
$$

where $\left\{v_{1}, q_{1}\right\}, 1=1 \ldots \mathrm{L}$, are the location vectors and probabilities characterising the heterogeneity distribution. The mass points (or combinations of mass points) and their associated probabilities are estimated with other model parameters. Each hazard rate contains a constant term. Accordingly, for identification purposes, the unobserved heterogeneity is modelled by normalising the first 5-tuple of location parameters to zero so that the estimated coefficient for the remaining unobserved types of individuals denotes the deviation from the constant term. For the estimation procedure, the probabilities $q_{l}$ are specified as logistic probabilities.

\section{Results}

The estimated model contains a large number of parameters, most of which are included solely for control purposes and are secondary to the topics discussed in this paper. Hence, although the full results are reported in Table 16 in Appendix, they are not all discussed in the text. The focus in this section is on key results regarding the impact of the UIS on employment and unemployment duration.

Overall, our MMPH model demonstrates its relevance with the significant differences between the patterns of duration dependence and the effects of the explanatory variables on each hazard rate. The likelihood function obtains its maxima at three mass-points in the distribution of unobserved heterogeneity. These support points are robustly identified on the basis of a large number of estimators with different starting values. The results are also highly robust as long as the number of support points remains between two and three. ${ }^{23}$ This may imply that the information content in the data relating to the distribution of the unobserved heterogeneity term is sufficient to ensure robust identification of the structural duration dependence in the hazard rates, as well as the effects of benefits on spell duration.

The MMHP model is estimated using a polynomial baseline for each hazard, ${ }^{24}$ and we also use some dummy variables to control for spikes observed at certain spell durations - see Figs. 1 and 2. Basically, months 3, 6, 9, 12, 24 and 36 for employment spells and months 6 and 10 for unemployment spells. For the sake of brevity, we do not display the predicted hazards in this section because we will present them with the results of our simulations in the robustness checks of the model (see Appendix A). The estimated layoff, quit and JJ-TC hazard rates show negative duration dependence. The estimated JJ-PC hazard rate shows positive duration dependence during the first

\footnotetext{
23 We also tried to estimate the model with four points of support, but there was no convergence in any of the estimations.

24 Alternatively, we estimated the model with a piece-wise constant specification of the baseline hazard to allow for greater flexibility. However, many of the duration variables were not identified for certain months because there were not enough exits observed for one of the competing exits.
} 
Table 5 Predicted mean exit rates by unobserved heterogeneity

\begin{tabular}{llllllll}
\hline $\begin{array}{l}\text { Contract } \\
\text { type }\end{array}$ & $\begin{array}{l}\text { Unobserved } \\
\text { heterogeneity }\end{array}$ & \multicolumn{2}{l}{ Employment } & & \multicolumn{2}{l}{ Unemployment } \\
\cline { 3 - 6 } & & $\begin{array}{l}\text { Layoff } \\
(\%)\end{array}$ & $\begin{array}{l}\text { Quit } \\
(\%)\end{array}$ & $\begin{array}{l}\text { JJ to } \\
\text { PC }(\%)\end{array}$ & $\begin{array}{l}\text { JJ to } \\
\text { TC }(\%)\end{array}$ & $\begin{array}{l}\text { To TC } \\
(\%)\end{array}$ & $\begin{array}{l}\text { To PC } \\
(\%)\end{array}$ \\
\hline TC & Type I & 7.37 & 1.41 & 2.90 & 3.86 & 9.76 & 0.21 \\
& Type II & 7.97 & 1.53 & 3.15 & 4.18 & 4.16 & 0.00 \\
& Type III & 18.37 & 3.71 & 7.37 & 9.99 & 19.25 & 0.11 \\
PC & Type I & 0.25 & 0.27 & 0.60 & 0.46 & 6.52 & 0.21 \\
& Type II & 0.27 & 0.29 & 0.65 & 0.50 & 2.27 & 0.00 \\
& Type III & 0.67 & 0.72 & 1.58 & 1.23 & 13.10 & 0.11 \\
\hline
\end{tabular}

These exit probabilities are computed at sample means

$T C$ temporary contract, $P C$ permanent contract, $J J P C$ job-to-job transition to a PC, $J J T C$ job-to-job transition to a TC

2 years of the contract. With the exception of the quit hazard rate, all hazard rates show spikes at specific contract durations, with the largest occurring at months 6 and 12. The estimated unemployment hazard rates also show a clear negative duration dependence.

\subsection{Unobserved heterogeneity and selection effects}

Unobserved heterogeneity is responsible for a substantial degree of variation in all estimated hazard rates (see Appendix A). Moreover, the MMPH model that we use conceals some interesting results which would remain unknown if the model is estimated separately for each labour market state. In Table 5, we display average estimated exit probabilities for each unobserved heterogeneity component (e.g., worker type). The information presented in this table demonstrates that $32 \%$ of the individuals in our sample are high turnover workers (mainly Type III workers in our analysis), i.e., they face higher employment and unemployment exit probabilities than other individuals. Note that these workers face employment and unemployment exit probabilities that are at least double the probabilities observed for the other workers. For instance, for the employment equation, the transitions probabilities for this worker type are: $18.37,3.71,7.37$ and $9.99 \%$, for the layoff, quit, JJ-PC and JJ-TC transition probabilities, respectively. For the unemployment equation, the transition probabilities are: 19.25 and $0.11 \%$ for the entrance into a temporary contract and into a permanent contract, respectively. The differences between the other two types of workers are smaller, although Type I individuals seem to be more stable because their employment exit probabilities are lower and their unemployment exit probabilities are higher than those of Type II workers.

\subsection{UIS system incidence on employment duration}

The empirical analysis presented in this section is based on the notion that the UIS might affect employment duration. Nevertheless, from a theoretical perspective, the 
Table 6 Parameters estimates for the UIS covariates (employment state)

\begin{tabular}{|c|c|c|c|c|c|c|c|c|}
\hline \multirow[t]{2}{*}{ Competing risks } & \multicolumn{2}{|l|}{ Layoff } & \multicolumn{2}{|l|}{ Quit } & \multicolumn{2}{|l|}{ JJ-PC } & \multicolumn{2}{|l|}{$\mathrm{JJ}-\mathrm{TC}$} \\
\hline & Coeff. & z-stat & Coeff. & z-stat & Coeff. & z-stat & Coeff. & z-stat \\
\hline \multicolumn{9}{|c|}{ Current contract: temporary } \\
\hline DurU & 0.1201 & 29.52 & 0.1370 & 16.42 & -0.0841 & -8.66 & -0.0640 & -9.75 \\
\hline DurB & -0.0938 & -18.75 & -0.2267 & -16.65 & 0.0535 & 17.22 & -0.0182 & 1.45 \\
\hline \multicolumn{9}{|c|}{ Current contract: permanent } \\
\hline DurU & -0.0115 & -0.91 & 0.1719 & 12.61 & 0.0185 & 1.28 & 0.0929 & 6.00 \\
\hline DurB & 0.0220 & 1.37 & -0.1726 & -7.54 & -0.0011 & -0.95 & -0.0483 & 2.37 \\
\hline
\end{tabular}

TC temporary contract, $P C$ permanent contract, $J J P C$ job-to-job transition to a PC, $J J T C$ job-to-job transition to a TC, DurU previous unemployment duration in logs, DurB previous benefit entitlement length (matching effect) in logs

sign of the predicted effect is ambiguous. First, employment duration might be negatively related to previous benefit length because benefits allow lengthier unemployment spells, which might have negative consequences for subsequent employment duration due to human capital depreciation or negative signalling effects (see Rebollo-Sanz 2011 for recent evidence for Spain). Second, employment duration might be positively related to benefits because of the "matching effect". That is, benefits allow the worker to devote more time to find a good, and therefore durable, match. We add a new dimension to this analysis and wonder whether these effects could vary between temporary workers and permanent workers. In particular, we assess whether unemployment benefits might favour job stability by encouraging the transition from temporary to permanent contracts.

Before analysing our results showing the impact of benefits on employment duration, it is appropriate to clarify how unemployment duration influences on subsequent job duration. Coefficient estimates (Table 6) lead us to conclude that unemployment duration negatively affects subsequent employment stability because outflows to unemployment increase with previous unemployment duration (either as layoffs or quits), whereas job-to-job transitions decrease, with the exception of transitions from permanent to temporary contracts, which seem to increase with unemployment duration. These results basically show that the quality of the match decreases as the duration of the previous unemployment spell increases, regardless of whether the worker is receiving benefits or not. However, the relevant question is not about the effect of past unemployment duration but about whether entitlement to and collection of unemployment benefits in the past may help workers access better jobs.

We now focus on the effects of receiving benefits. The results show that for workers holding a temporary contract, benefits reduce the layoff as well as the quit probability. For workers holding a permanent contract we again obtain that benefit reduce the probability of quitting but they do not reduce the probability of being layoff. Hence, from the side of the worker, benefits clearly help to find a better match. Coefficient estimates also show that unemployment benefits favor workers holding a temporary contract indirectly. That is, the probability of having a job-to-job transition increases 
Incidence of Unemployment Duration on the Employment exit probability
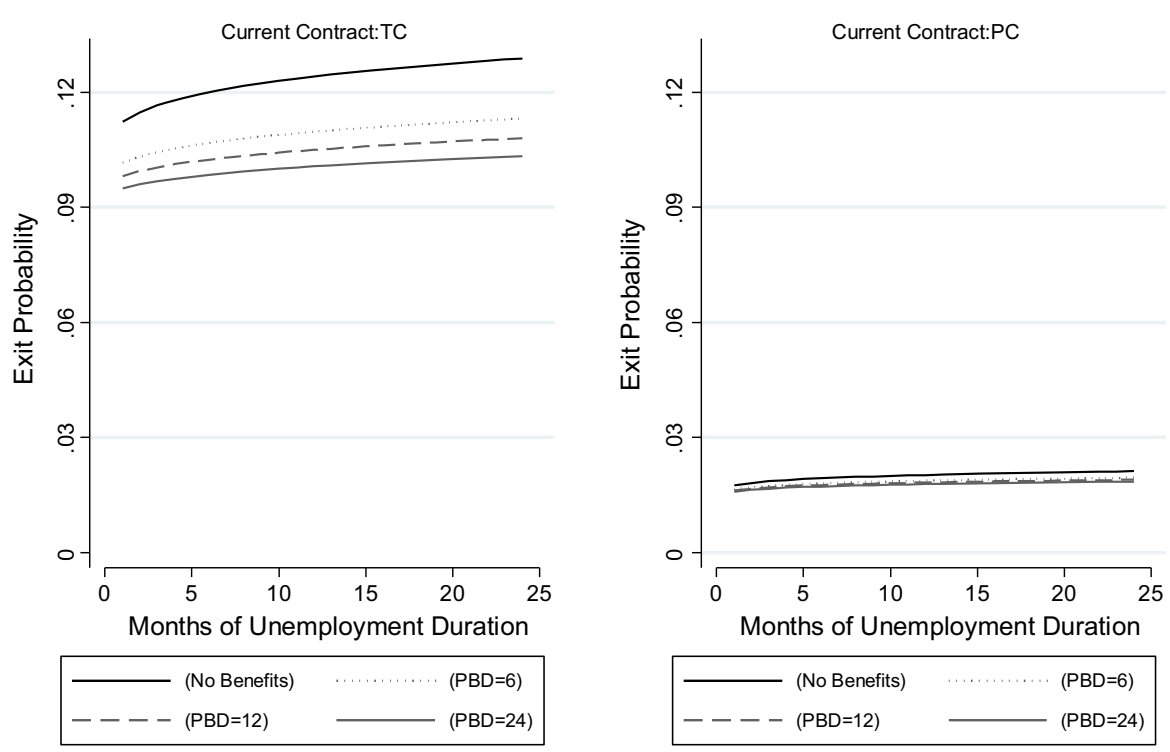

Employment duration=10 months; PBD=Previous Benefit Entitlement Length

Fig. 3 Measuring the incidence of the unemployment spell on employment

with the length of the entitlement. Thus, we find evidence that unemployment benefits favor job stability not only by reducing the outflows to unemployment but also increasing the inflows into a permanent contract. This last result is not found for workers holding a permanent contract and coefficient estimates are not always statistically significant for workers holding permanent contracts.

To illustrate these results, we display in Fig. 3 the employment exit probability (computed at sample means) in relation to previous unemployment duration for different benefit entitlements. Note the increasing pattern of employment exit probability from a temporary contract as the period of unemployment lengthens. This figure also indicates that insured workers tend to have more stable labour market careers. Notice that the differences are large. For instance, for workers with an unemployment spell of 1 month, the monthly employment exit probability is around $11.5 \%$ if she does not receive benefits and it drops to $9.5 \%$ when she is entitled to receive 24 months of benefits. Hence, although we know that lengthier unemployment spells lead to larger outflows from employment the importance of the effect seems to differ with respect to insured and non-insured workers. Now let's compute the employment exit probability at each competing risk to better understand the results.

In Table 7, we display the estimated employment transition probability to each competing risk in relation to previous unemployment duration for insured and non-insured workers. Let's look at the results for workers holding a temporary contract. The results show that insured workers tend to have more stable labour market careers because they face lower exits to unemployment (either as layoffs or as quits) and slightly larger tran- 
Table 7 Estimated employment exit probability in relation to previous unemployment duration

\begin{tabular}{|c|c|c|c|c|c|c|c|c|}
\hline \multirow[t]{2}{*}{ Unempl. duration } & \multicolumn{2}{|l|}{ Layoff } & \multicolumn{2}{|l|}{ Quit } & \multicolumn{2}{|l|}{$\mathrm{JJ}$ to $\mathrm{PC}$} & \multicolumn{2}{|l|}{$\mathrm{JJ}$ to $\mathrm{TC}$} \\
\hline & $\begin{array}{ll}\text { NO UIS } \\
(\%)\end{array}$ & $\begin{array}{l}\text { UIS } \\
(\%)\end{array}$ & $\begin{array}{l}\text { NO UIS } \\
(\%)\end{array}$ & $\begin{array}{l}\text { UIS } \\
(\%)\end{array}$ & $\begin{array}{l}\text { NO UIS } \\
(\%)\end{array}$ & $\begin{array}{l}\text { UIS } \\
(\%)\end{array}$ & $\begin{array}{ll}\text { NO UIS } \\
(\%)\end{array}$ & $\begin{array}{l}\text { UIS } \\
(\%)\end{array}$ \\
\hline \multicolumn{9}{|c|}{ Current contract: TC } \\
\hline 3 & 6.49 & 5.52 & 1.68 & 1.13 & 1.74 & 1.87 & 4.15 & 4.02 \\
\hline 6 & 7.03 & 5.98 & 1.85 & 1.24 & 1.64 & 1.76 & 3.98 & 3.85 \\
\hline 12 & 7.97 & 6.48 & 2.03 & 1.36 & 1.55 & 1.66 & 3.81 & 3.69 \\
\hline 24 & 8.24 & 7.02 & 2.23 & 1.49 & 1.46 & 1.61 & 3.64 & 3.53 \\
\hline \multicolumn{9}{|c|}{ Current contract: PC } \\
\hline 3 & 0.44 & 0.45 & 0.33 & 0.24 & 0.57 & 0.57 & 0.47 & 0.43 \\
\hline 6 & 0.43 & 0.45 & 0.37 & 0.28 & 0.58 & 0.58 & 0.50 & 0.46 \\
\hline 12 & 0.43 & 0.45 & 0.42 & 0.30 & 0.59 & 0.59 & 0.53 & 0.49 \\
\hline 24 & 0.43 & 0.44 & 0.47 & 0.34 & 0.60 & 0.60 & 0.57 & 0.52 \\
\hline
\end{tabular}

This exit probability is computed at the mean sample characteristics for temporary and permanent contracts, respectively. We fix the spell duration at 10 months

sition probabilities to new jobs with permanent contracts. For example, the estimated layoff probability is $5.52 \%$ when previous unemployment episode lasted three months and unemployment benefits were available; if the previous unemployment duration remains the same but unemployment benefits were not available, the estimated layoff probability is $6.49 \%$. These rates move up to 6.48 and $7.97 \%$, respectively, when previous unemployment duration increases up to 12 months. Furthermore, the probability of quitting decreases when unemployment benefits were received. Job-to-job flows are also affected, but to a lesser extent than outflows to unemployment. Interestingly, JJPC flows increase for benefit receivers, whereas flows to temporary contracts decrease. Hence, we obtain clear evidence that the availability of unemployment benefits seems to increase job stability, at least for temporary workers. That is, previously insured workers benefit from a larger probability of remaining in the same job or entering into a more stable job than non-insured ones.

The results obtained for employees holding permanent contracts are much smaller in absolute value, for both unemployment duration and the effect of UIS on employment stability, which may demonstrate that once a worker has obtained a permanent contract, previous unemployment duration becomes much less relevant to employment stability.

Next, we focus on the coefficient estimates for benefit entitlement duration. Table 6 shows that these coefficient estimates are statistically significant and have the expected sign for temporary contracts. In particular, these coefficient estimates show that lengthier benefit periods seem to favour employment stability, because outflows to unemployment decrease and job-to-job transition flows increase. These results are consistent with the models of Marimon and Zilibotti (1999) and Acemoglu and Shimer (2000) and with the results presented in Belzil (2001), Centeno (2004) and Tatsiramos (2009). In contrast, coefficient estimates are not always statistically significant for the sample of permanent contracts. 
Table 8 Estimated employment exit probability in relation to UIS entitlement

\begin{tabular}{llllll}
\hline & Layoff $(\%)$ & Quit $(\%)$ & JJ-PC $(\%)$ & JJ-TC (\%) & Empl. duration \\
\hline $\begin{array}{l}\text { Contract type: TC } \\
\text { Non-insured }\end{array}$ & 7.03 & 1.85 & 1.64 & 3.98 & 5.96 \\
$\begin{array}{l}\text { UIS entitlement } \\
4\end{array}$ & 6.20 & 1.36 & 1.73 & 3.88 & 6.59 \\
6 & 5.98 & 1.24 & 1.76 & 3.85 & 6.77 \\
8 & 5.83 & 1.16 & 1.78 & 3.83 & 6.90 \\
12 & 5.62 & 1.06 & 1.81 & 3.81 & 7.08 \\
24 & 5.27 & 0.91 & 1.86 & 3.76 & 7.39 \\
Contract Type: PC & & & & & \\
Non-insured & 0.44 & 0.36 & 0.62 & 0.37 & 42.52 \\
UIS entitlement & & & & & \\
4 & 0.45 & 0.29 & 0.58 & 0.47 & 43.25 \\
6 & 0.46 & 0.28 & 0.58 & 0.46 & 43.44 \\
8 & 0.46 & 0.25 & 0.58 & 0.45 & 43.57 \\
12 & 0.46 & 0.24 & 0.58 & 0.44 & 43.73 \\
24 & 0.47 & 0.21 & 0.58 & 0.43 & 44.00 \\
\hline
\end{tabular}

This exit probability is computed at sample mean characteristics and for an unemployment episode of 6 months. Exit probabilities computed at employment duration equals to 10 months

In Table 8, we display the estimated employment exit probability in relation to benefit entitlement duration for each competing risk. It could be that benefit recipients have better chances than non-recipients of obtaining permanent job offers once employed. That is, benefit recipients accepted a temporary job offer expecting a "promotion" into a permanent contract in the near future. Note that our sample includes transitions from a temporary to a permanent contract within the same or different firm and as Rebollo-Sanz (2011) has shown, they are more frequent within the same firm in Spain. In particular, during 2000-2007, $83 \%$ of the transitions from temporary to permanent contracts took place at the same firm.

We focus on the results for temporary workers because they represent the majority of employment outflows and because the matching effect could be of great importancein terms of job stability-to a worker that ends a temporary contract and enters into a permanent contract. As observed in this table, the relationship between the matching effect and entitlement duration is positive but it does not seem to be very strong. We obtain decreases in the layoff probability from $7.03 \%$ for previously uninsured workers to $6.20 \%$ for insured workers whose entitlement was four months and to $5.27 \%$ for insured workers whose entitlement was twenty for months-drop of $15 \%$ in the layoff probability. The incidence on the job flows is much lower. The probability of a JJ-PC transition increases slightly from $1.64 \%$ for previously uninsured workers to $1.73 \%$ for insured workers whose entitlement was four months and to $1.86 \%$ for insured workers whose entitlement was twenty for months - an increase in the job-to-job transition probability of $7 \%$. The probability of a JJ-TC transition decreases slightly 
from $3.98 \%$ for previously uninsured workers to $3.88 \%$ for insured workers whose entitlement was four months and to $3.76 \%$ for insured workers whose entitlement was twenty for months. ${ }^{25}$ In terms of expected duration, our results show that average employment duration for an uninsured worker is 5.96 months, for an insured worker with four months of benefits is 6.59 months and for entitlements of twenty for months is 7.39 months. Hence, the above results seem to demonstrate that insured workers benefit from longer employment duration relative to uninsured workers, although the magnitude of the effect is not large. In other words, the elasticity of employment duration to benefit entitlement length is low in Spain.

Hence, our results show that benefits might improve employment stability for temporary workers and that this increase comes from a pure matching effect-i.e., insured workers have longer job tenure than uninsured workers-and from a greater chance of entering into a new job with a permanent contract. We find that employment duration for benefit recipients can be between 10 and $20 \%$ longer than for non-recipients when workers enter into temporary contracts. Hence, jobs that are found when receiving benefits last longer than jobs found by non-recipients. These differences are lower for workers who obtain a permanent contract in the new job. However, the duration of benefit entitlement by itself does not seem to be highly relevant in terms of subsequent job duration.

\subsection{UIS system effects on unemployment duration}

In general terms, all UIS variables in the unemployment equation are statistically significant (see Table 9), which suggests that benefits affect the timing of outflows to employment and that this effect varies with unemployment duration. The usual findings, that unemployment duration increases with the length of the UIS entitlement period and that the unemployment hazard rate rises as benefit expiration approaches (Meyer 1990; Belzil 2001; Roed and Zhang 2003; Tatsiramos 2009; Boone et al. 2009; Rebollo-Sanz 2012) are also obtained in this estimation. ${ }^{26}$

To illustrate the results obtained we compute the unemployment exit probability using coefficient estimates. Figure 4 shows the estimated unemployment exit probability in relation to unemployment duration for three alternative situations: (1) uninsured workers; (2) insured workers with 6 months of entitlement (UIS = 6); and (3) insured workers with 8 months of entitlement (UIS $=8$ ). In Table 10, we display the same estimated unemployment exit probability but for each competing risk.

\footnotetext{
25 We estimated the same model but including a dummy variable that takes a value of one when the worker exited the previous spell of unemployment before benefits were exhausted and takes a value of zero otherwise. We do not find a statistically significant effect on subsequent employment duration. Alternatively, we also estimated this model but including a dummy variable that takes a value of one if the worker exited the unemployment at the time that benefits were exhausted and takes a value of zero otherwise. In this second case we found a significant positive effect of benefits on subsequent employment duration. This is in line with the results presented in Centeno (2004) who shows that there is some heterogeneity in the matching effect.

${ }^{26}$ In Rebollo-Sanz (2012), one can find a deeper analysis of the exhaustion effects in the Spanish Labour Market by differentiating between the effect of benefits on unemployment exits to jobs at the same firm (recalls) and exits to jobs at a new firm.
} 
Table 9 Estimation results for the unemployment state

\begin{tabular}{|c|c|c|c|c|}
\hline \multirow[t]{2}{*}{ Competing risks } & \multicolumn{2}{|c|}{ Exit to a TC } & \multicolumn{2}{|c|}{ Exit to a PC } \\
\hline & Coeff & Z-stat & Coeff & Z-stat \\
\hline \multicolumn{5}{|l|}{ UIS variables } \\
\hline \multicolumn{5}{|c|}{ Previous contract: TC } \\
\hline DurB & -0.4329 & -55.3 & -0.4786 & -10.2 \\
\hline DurB*DurU & 0.0605 & 13.4 & 0.1078 & 2.9 \\
\hline ExB & 0.0913 & 6.8 & 0.0804 & 1.8 \\
\hline \multicolumn{5}{|c|}{ Previous contract: PC } \\
\hline DurB & -0.5787 & -42.5 & -0.9269 & -12.1 \\
\hline DurB*DurU & 0.1003 & 6.7 & 0.0835 & 1.7 \\
\hline ExB & 0.1979 & 15.7 & -0.3530 & -2.4 \\
\hline
\end{tabular}

DurB months to exhaust benefits, $E x B * D u r U$ interaction of DurB with unemployment length in $\operatorname{logs}, E x B$ exhaustion of benefits

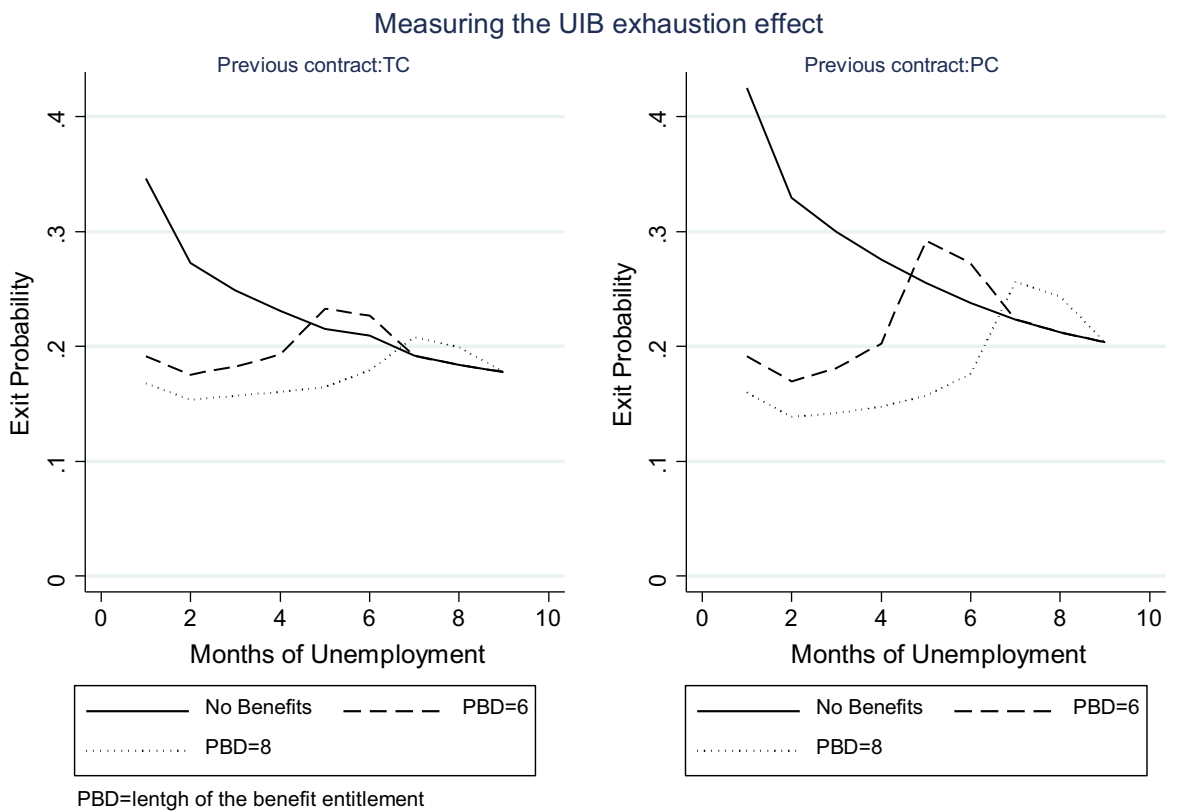

Fig. 4 Estimated unemployment exit probability in relation to the UIS entitlement length

Our results show that the behavioural effects of benefits on unemployment duration are substantial. Firstly, the results clearly shows the so-called "disincentive effect" of benefits, meaning that the unemployment exit probability is much lower for insured workers than for uninsured ones. Similarly, we obtain that the unemployment exit probability decreases with benefit entitlement duration. For example, for a temporary worker in the first month of an unemployment spell, the rate of exit to a temporary 
Table 10 The estimated unemployment exit probability in relation to unemployment duration and UIS entitlement length

\begin{tabular}{|c|c|c|c|c|c|c|c|c|}
\hline \multirow[t]{2}{*}{ Unemployment duration: } & \multicolumn{4}{|c|}{ Exit To TC } & \multicolumn{4}{|c|}{ Exit To PC } \\
\hline & $1(\%)$ & $4(\%)$ & $8(\%)$ & $12(\%)$ & $1(\%)$ & $4(\%)$ & $8(\%)$ & $12(\%)$ \\
\hline \multicolumn{9}{|l|}{ Previous contract:TC } \\
\hline Non-insured & 33.32 & 22.39 & 17.69 & 16.13 & 1.32 & 0.67 & 0.68 & 0.76 \\
\hline \multicolumn{9}{|l|}{ Insured: entitlement } \\
\hline 4 & 22.48 & 24.20 & 17.69 & 16.13 & 0.78 & 0.73 & 0.68 & 0.76 \\
\hline 8 & 16.26 & 15.61 & 19.18 & 13.34 & 0.52 & 0.42 & 0.73 & 0.76 \\
\hline 12 & 13.60 & 12.95 & 13.34 & 17.50 & 0.42 & 0.33 & 0.47 & 0.82 \\
\hline \multicolumn{9}{|l|}{ Previous contract: PC } \\
\hline Non-insured & 39.81 & 25.57 & 19.38 & 17.15 & 2.68 & 1.99 & 1.84 & 1.80 \\
\hline \multicolumn{9}{|l|}{ Insured: entitlement } \\
\hline 4 & 23.93 & 30.13 & 19.38 & 17.15 & 0.99 & 1.39 & 1.84 & 1.80 \\
\hline 8 & 15.36 & 14.08 & 23.03 & 17.15 & 0.46 & 0.66 & 1.21 & 1.80 \\
\hline 12 & 12.22 & 10.29 & 11.08 & 20.45 & 0.30 & 0.38 & 0.66 & 1.26 \\
\hline
\end{tabular}

contract is approximately 10,16 and 19 percentage points lower for insured workers (compared to uninsured workers) with entitlement durations of 6,8 and 12 months, respectively. The transition probability to a temporary contract decreases even more for workers who previously held a permanent contract, by approximately 16, 24 and 27 percentage points, respectively. However, these differences in exit probability between temporary and permanent contracts point that these results can also be interpreted in terms of liquidity constraints-more important for temporary workers-instead of exclusively in terms of "disincentive effects" (Chetty 2008). Thus, it could be that workers without benefits need to accept the first job offered, whereas insured workers can keep searching for a suitable or good match ${ }^{27}$.

Secondly, for insured workers, the unemployment exit probability slowly decreases until the time benefit exhaustion approaches and sharply increases near the time benefits are exhausted. That is, either the insured worker exits at the beginning of the unemployment spell, or he waits until benefits are exhausted - the latter option being more common. The exhaustion effect reflects the joint effect of falling reservation wages and rising job search intensity at the time of exhaustion. Note that at the time of exhaustion, the unemployment exit rate increases even higher than the rate for uninsured workers.

Focusing on the exhaustion effect, note that for the cases represented in Fig. 4, the unemployment exit probability increases by approximately $8-11$ percentage points at the time the benefits are exhausted relative to one month before exhaustion. Interestingly, this exhaustion effect is larger for workers who previously held a permanent contract. Again we argue that this could be an evidence of the importance of the liquid-

\footnotetext{
27 Chetty (2008) shows that $60 \%$ of the increase in unemployment durations caused by UI benefits is due to a "liquidity effect" rather than distortions on marginal incentives to search ("moral hazard").
} 
ity constraints on explaining unemployment duration. Workers who hold a permanent contract would probably face lower liquidity constraints than temporary ones since they benefited from severance payments when entering into unemployment. However, in many cases temporary workers do not receive severance payments and, when they receive severance payments, these are notably lower than the severance payments of permanent contracts.

Table 10 also shows the importance of the "exhaustion effect" for each competing risk, which seems to be strongly related to exits to temporary contracts. ${ }^{28}$ Again, we obtain that the difference in the exit probability between insured and uninsured workers is larger for workers who previously held permanent contracts than for workers who previously held temporary contracts. Thus, our results indicate that unemployment benefits might favour job stability by allowing temporary workers to keep searching for a good match. However, when benefits expire, the worker accepts the first job offered, mostly due to liquidity constraints.

Some previous empirical papers have estimated the exhaustion effect of benefits for Spain. For instance, Rebollo-Sanz (2012) differentiates between recalls and entry into new jobs and get that the unemployment hazard rate shows a strong spike for entry into new jobs whereas for recalls the spike is much lower. ${ }^{29}$ In Arranz and Muro $(2004)^{30}$ the exhaustion effect is notably higher to the one presented in this paper. However, as Card et al. (2007) has shown, the way unemployment spells are measured has a large effect on the magnitude of the spike at exhaustion. Particularly, spikes are typically much smaller when spell length is defined by the time to next job than when it is defined by the time spent on the unemployment benefit system. For instance, they find that in Austria, the exit rate from registered unemployment rises by over $200 \%$ at the expiration of benefits while the re-employment hazard rate rises by only $20 \%$. The difference between these two measures arises because many individuals leave the unemployment register after their benefits expire without returning to work.

In our exercise, our duration measure is time to find a job. ${ }^{31}$ To illustrate the importance of this type of data when analysing the impact of unemployment benefits on the exit from unemployment, we have also estimated our model using data only for benefit recipients and truncating our duration measure at the time the worker exhausts her benefits-either assistance or contribution ones. As can be seen in Table 11, we get that the exhaustion effect is notably stronger in this new estimation than in the

\footnotetext{
28 Note that in the statistical section we show that almost all unemployment episodes end in temporary contracts.

29 She obtains that, for male temporary workers, the recall hazard rate increases by 6.66 percentage points, while the new job hazard rate increases by 11.39 percentage points.

30 Arranz and Muro (2004) estimate the exhaustion effect for Spain using the HSIPRE (Histórico del Sistema de Prestaciones por Desempleo) administrative database. They obtain that the hazard rate rises dramatically when UI benefit lapses approaches. Note, however that, as stated by the authors, one disadvantage of their database is the lack of information about the labour force status the days after unemployment benefits are exhausted.

31 Existing studies of labor market transitions near the point of unemployment benefit exhaustion have used three alternative measures of duration: the length of benefit receipt, the duration of the registered unemployment, and the duration of non-employment (time to next job). The last one is the one used in our paper.
} 
Table 11 Measurement error when identifying the exhaustion effect

\begin{tabular}{|c|c|c|c|c|}
\hline \multirow[t]{2}{*}{ Competing risks } & \multicolumn{2}{|c|}{ Exit to a TC } & \multicolumn{2}{|c|}{ Exit to a PC } \\
\hline & Coeff & z-stat & Coeff & Z-stat \\
\hline \multicolumn{5}{|l|}{ UIS variables } \\
\hline \multicolumn{5}{|l|}{ Previous contract: TC } \\
\hline ExB (full sample) & 0.0913 & 6.8 & 0.0804 & 1.8 \\
\hline ExB (subsample: benefit recipients) & 0.5977 & 23.74 & 0.9808 & 5.1 \\
\hline \multicolumn{5}{|l|}{ Previous contract: $\mathrm{PC}$} \\
\hline ExB (full sample) & 0.1979 & 15.7 & -0.3530 & -2.4 \\
\hline ExB (subsample: benefit recipients) & 1.2923 & 21.47 & 1.3606 & 4.9 \\
\hline
\end{tabular}

For the subsample of benefit receipts, the duration is censored at the time the worker exhausts her benefits

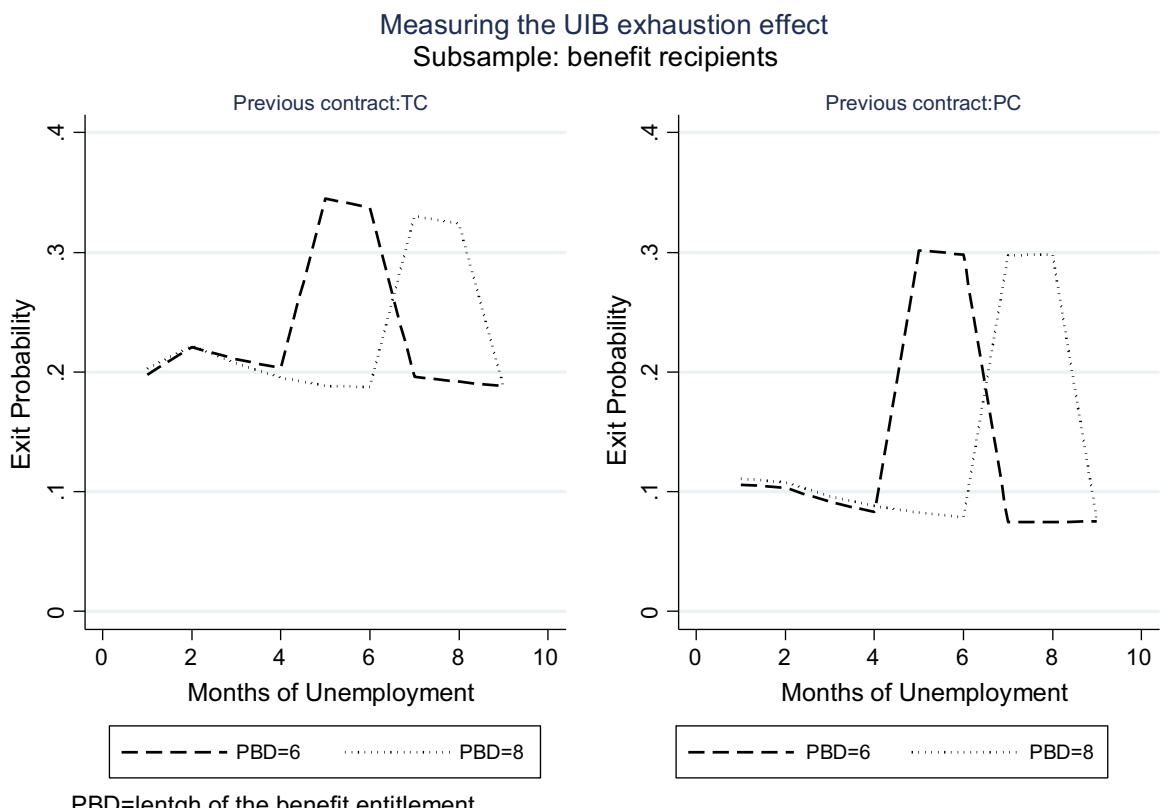

Fig. 5 Estimated unemployment exit probability in relation to the UIS entitlement length (subsample of benefit recipients)

former one. ${ }^{32}$ For instance, the coefficient of the exhaustion effect changes from 0.09 to 0.59 for temporary workers who exit to a temporary contract and from 0.08 to 0.98 for the exit to a permanent contract. This implies that the unemployment exit probability increases by around $75 \%$ for temporary contracts and by $200 \%$ for permanent contracts at the time of exhaustion relative to one month before exhaustion. Figure 5

\footnotetext{
32 For sake of concreteness we omit the complete set of coefficient estimates. They can be provided upon request.
} 
Table 12 Parameters estimates for occurrence dependence terms

\begin{tabular}{llllcc}
\hline & \multicolumn{2}{l}{ Number of PC } & & \multicolumn{2}{l}{ Number of job interruptions } \\
\cline { 2 - 3 } \cline { 5 - 6 } & Coeff. & z-stat & & Coeff. & z-stat \\
\hline Employment state & & & & \\
Layoff & -0.0282 & -7.01 & & 0.0807 & 88.61 \\
Quit & -0.0228 & -2.90 & & 0.0870 & 43.66 \\
JJ-PC & 0.1291 & 17.19 & & -0.0904 & -32.8 \\
JJ-TC & -0.0864 & -14.2 & & 0.0044 & 3.51 \\
Unemployment state & & & & 6.92 \\
TC & -0.0187 & -4.57 & & 0.0064 & -11.76 \\
PC & 0.2368 & 11.92 & & -0.0848 & \\
\hline
\end{tabular}

displays the estimated unemployment exit probability in relation to unemployment duration for three alternative situations: (1) uninsured workers; (2) insured workers with 6 months of entitlement (UIS =6); and (3) insured workers with 8 months of entitlement (UIS = 8). The comparison of this Fig. 5 with Fig. 4 clearly illustrates the importance of the bias committed when using data only on benefit recipients. Hence, we confirm here that, at least for the Spanish case, the exhaustion effect is overestimated when benefit receipt is used as a duration measure.

\subsection{Labour market history variables: occurrence dependence}

The coefficients of the covariates used to control for occurrence dependence- - the number of previous permanent contracts and the number of unemployment spellsare displayed in Table 12 for both employment and unemployment states. These coefficients are all statistically significant and display the expected signs. They show that workers who have previous labour market histories characterised by job spells with permanent contracts and low numbers of job interruptions tend to have better subsequent employment prospects than their counterparts. Their outflows from employment are lower and they have higher probabilities of making job-to-job transitions into new permanent contracts.

The corresponding estimated employment exit probabilities and unemployment exit probabilities for different accumulated, open-ended contracts and job interruptions are displayed in Tables 13 and 14, respectively. In particular, Table 13 shows that the number of previous open-ended contracts favours job stability because it negatively influences the exits to unemployment (layoffs and quits) and JJ-TC transitions and positively influences the probability of entering into a job associated with a permanent contract. In terms of unemployment outflow, we see that the probability of exit into a new permanent contract increases.

Table 14 also shows that, as expected, the number of job interruptions negatively affects future employment stability because the outflow from unemployment decreases and that the probabilities of being laid off or experiencing a job-to-job transition 
Table 13 Incidence of accumulated open-ended contract on employment and unemployment outflows

\begin{tabular}{|c|c|c|c|c|c|c|}
\hline & \multicolumn{4}{|c|}{ Employment exit probability } & \multicolumn{2}{|c|}{ Unemployment exit probability } \\
\hline & Layoff (\%) & Quit (\%) & JJ-PC (\%) & JJ-TC (\%) & $\mathrm{TC}(\%)$ & $\mathrm{PC}(\%)$ \\
\hline \multicolumn{7}{|c|}{ Current/previous contract: TC } \\
\hline 1 & 5.08 & 1.22 & 1.79 & 2.43 & 17.37 & 0.09 \\
\hline 2 & 4.94 & 1.19 & 2.04 & 2.23 & 17.09 & 0.12 \\
\hline 3 & 4.81 & 1.16 & 2.31 & 2.05 & 16.82 & 0.16 \\
\hline 4 & 4.68 & 1.14 & 2.63 & 1.89 & 16.55 & 0.20 \\
\hline 5 & 4.55 & 1.11 & 2.99 & 1.73 & 16.28 & 0.26 \\
\hline 6 & 4.43 & 1.09 & 3.39 & 1.59 & 16.02 & 0.33 \\
\hline \multicolumn{7}{|c|}{ Current/previous contract: PC } \\
\hline 1 & 0.32 & 0.22 & 0.54 & 0.28 & 8.44 & 0.46 \\
\hline 2 & 0.31 & 0.21 & 0.62 & 0.25 & 8.33 & 0.61 \\
\hline 3 & 0.30 & 0.21 & 0.70 & 0.23 & 8.21 & 0.80 \\
\hline 4 & 0.29 & 0.20 & 0.80 & 0.21 & 8.10 & 1.06 \\
\hline 5 & 0.29 & 0.20 & 0.91 & 0.19 & 7.98 & 1.41 \\
\hline 6 & 0.28 & 0.19 & 1.04 & 0.18 & 7.87 & 1.86 \\
\hline
\end{tabular}

Exit probabilities measured at mean of sample characteristics

Table 14 Incidence of accumulated job interruptions on employment and unemployment outflows

\begin{tabular}{|c|c|c|c|c|c|c|}
\hline & \multicolumn{4}{|l|}{ Employment } & \multicolumn{2}{|c|}{ Unemployment } \\
\hline & Layoff (\%) & Quit (\%) & $\mathrm{JJ}-\mathrm{PC}(\%)$ & $\mathrm{JJ}-\mathrm{TC}(\%)$ & $\mathrm{TC}(\%)$ & $\mathrm{PC}(\%)$ \\
\hline \multicolumn{7}{|c|}{ Current contract: TC } \\
\hline 1 & 4.35 & 1.02 & 1.98 & 2.57 & 17.36 & 0.10 \\
\hline 2 & 4.70 & 1.11 & 1.81 & 2.58 & 17.49 & 0.09 \\
\hline 3 & 5.09 & 1.20 & 1.66 & 2.59 & 17.54 & 0.07 \\
\hline 4 & 5.55 & 1.30 & 1.51 & 2.60 & 17.65 & 0.07 \\
\hline 5 & 5.95 & 1.41 & 1.38 & 2.62 & 17.76 & 0.07 \\
\hline 6 & 6.43 & 1.52 & 1.26 & 2.63 & 17.87 & 0.06 \\
\hline \multicolumn{7}{|c|}{ Current contract: PC } \\
\hline 1 & 0.30 & 0.20 & 0.56 & 0.28 & 10.69 & 0.07 \\
\hline 2 & 0.33 & 0.22 & 0.51 & 0.28 & 10.76 & 0.06 \\
\hline 3 & 0.36 & 0.24 & 0.46 & 0.28 & 10.83 & 0.06 \\
\hline 4 & 0.39 & 0.26 & 0.42 & 0.28 & 10.90 & 0.06 \\
\hline 5 & 0.42 & 0.28 & 0.39 & 0.28 & 10.97 & 0.05 \\
\hline 6 & 0.46 & 0.31 & 0.35 & 0.28 & 11.04 & 0.04 \\
\hline
\end{tabular}

Exit probabilities measure at mean of sample characteristics

to a new temporary contract increase considerably. The largest effect is found for layoffs. For example, the monthly layoff probability increases from $4.35 \%$ for one job interruption to $6.43 \%$ for six job interruptions. 
Note that the number of job interruptions seems to be a relatively important determinant of employment stability compared to the results found for some of the UIS parameter estimates. In our estimation, entitlement to and duration of benefits affect the probability of having a job interruption, and the number of job interruptions affects subsequent employment stability. Hence, to understand the dynamic effects of entitlement duration on employment stability, the number of job interruptions and openended contracts should be taken into account.

\section{An illustration of the results through simulations}

The analysis presented in Sect. 6 does not result in a complete understanding of the overall effect of UIS entitlement duration on labour market stability. The mediumand long-term effects of the UIS system can differ from the short-term impact when employment duration depends on previous labour market history. Moreover, we have shown that previous labour market history seems to be even more relevant to explain current employment stability than the UIS. To gain insight into the dynamics of these effects and to get information about which of the different alternative effects of benefits on employment stability are dominant, we propose using some simulation exercises.

Because the reliability of these simulations depends on the capacity of our event history model to predict the realised labour market transitions, we previously prepared a report of goodness-of-fit checks of the estimated model. The description of the simulation performed for the goodness-of-fit analysis and the results are included in Appendix B. The primary conclusion from the goodness-of-fit analysis is that our empirical model is well able to reproduce sample transitions and average employment and unemployment spell durations.

\subsection{Simulations of policy interventions}

We propose here an exercise comprising an analysis of the effect of reducing, and alternatively, increasing, UIS entitlement length duration relative to the current status quo in Spain. Our main goal is to illustrate the previously described effects of the UIS on employment and unemployment duration as well as on other elements that influence employment stability. We are aware that our reduced-form duration model cannot offer an answer in terms of causal evaluation, but still we think it is interesting to perform the model to gain a deeper insight into the different results presented thus far. To summarise, we have found that previous job interruptions negatively affect job stability, and this effect increases with unemployment duration for non-recipients of benefits. On the contrary, UIS recipients might have lengthier employment spells than non-recipients, but this effect depends on previous unemployment duration and benefit entitlement length. In addition, becoming eligible for benefits may increase the outflows from employment. These results do not offer a clear answer in terms of the capacity of the UIS to encourage stable labour market paths. For that purpose, we simulate the estimated model for alternative UIS regimes. Specifically, apart from solving for the current design of the UIS system in Spain (Status Quo), we simulate 
the following policies: (1) a $50 \%$ decrease in benefit entitlement duration ${ }^{33}$; (2) a $50 \%$ increase in entitlement duration; and (3) an increase in PC offers modelled as a $20 \%$ decrease in the difference between the transitions (both from employment and unemployment) to a permanent contract and the ones to a temporary contract. ${ }^{34}$

The relevance of this last simulation exercise is revealed in Table 2 and Fig. 2. As illustrated in Table 2 the difference between the transition probabilities into a permanent contract versus a temporary one is very large not only from employment (11.4\% to a PC vs. $20.3 \%$ to a TC) but mainly from unemployment (1.8\% to a PC vs. $91.4 \%$ to a TC). In this exercise we reduce these differences by $20 \%$ in order to evaluate whether employment stability could change for reasons other than variations in the UIS and whether the gains in employment stability could be larger or smaller than the gains achieved with the previous change in the UI entitlement. From Krebs and Scheffel (2013), Krause and Uhlig (2012) or Launov and Wälde (2013) one can learn that it might be better to introduce reforms addressed to foster the labour demand and to improve the quality and quantity of active labour market policies as means to reduce job turnover and mean unemployment duration. With this simulation we are trying to illustrate this idea. Hence, the main goal is to confront a change in unemployment benefits with the potential effects of moving from a dual to a more stable labour market, that is, one where permanent contracts are more likely, as it is the case in the majority of OECD countries.

The simulation process is similar to the one performed for the goodness-of-fit exercise described in Appendix B. In particular, we can construct individual labour market histories for the alternative UIS designs described above, which are then used to predict the effects of policy changes on two main parameters: job turnover and overall employment and unemployment duration. This simulation is executed for certain types of individuals defined by specific observed characteristics. In particular, we divide the sample by age ( $<30-, 30-45$-, and $>45$-years-old), qualification at first job spell (lowand high-skill) and type of contract held in the first job. In all cases, we assume the individual is a full-time worker in the private sector. The variables related to the UIS system that control for labour market paths (i.e., number of job interruptions, number of permanent contracts, etc.) and time-varying individual variables, such as labour market experience, are endogenously determined within the simulation., The rest of the individual (exogenous) observed characteristics are computed at the sample averages specific to each group and remain constant throughout the simulation, with the exception of the worker's age. Each worker's labour market history is simulated 1,000

\footnotetext{
33 For example, an entitlement 6 months in the status quo would decrease to 3 months with the proposed reform. The same rule applies to any other entitlement duration.

34 That is, for each individual, we compute the transition probability from employment/unemployment to each type of contract in the status quo. Then, we compute the difference between these two transition probabilities, at the individual level. This simulation comprises a drop in this gap of $20 \%$. This implies a drop in the probability of transitioning to a temporary contract and an increase in the probability of transitioning to a permanent contract, keeping constant the rest of transitions in the model. Hence, we are only varying the weight of exits to permanent contracts relative to temporary contracts in order to simulate an alternative framework where permanent employment is more likely.
} 
times during a 60-month period. The present simulation exercise therefore accounts for medium-term effects. ${ }^{35}$

Based on our simulations, we compute the average number of unemployment and employment episodes, mean employment and unemployment duration, the share of workers that obtain a permanent contract and the total months of time employed during the sample frame (60 months). Interestingly, we can also use this simulation to compute the financial balance of the benefit system at the individual level (UIS individual balance). To do this, we use the rules of the Spanish Social Security system. That is, the revenue of the system comes from workers' benefit contributions, which represent $8.3 \%$ of their monthly wages. The costs of the system depend on the length of time the individual is unemployed, if any. Specifically, when she is unemployed, she receives $70 \%$ of her previous wages during the first 6 months and $60 \%$ of previous wages from the 7 th month onward, with a maximum duration of 24 months. The results are presented in Table 15. For the sake of brevity, we only present results for low-skilled workers who start in the labour market with a temporary contract because they are the workers who suffer the largest degrees of job turnover and therefore are affected to the greatest extent by the UIS system design. ${ }^{36}$ Furthermore, model estimates are relevant for temporary workers whereas for permanent contract workers coefficients are not always statistically significant. The results are presented in terms of the sample means and percentiles 25 and 75 for each outcome variable.

A central conclusion from our simulation exercises is that when UIS entitlement duration drops, the overall time spent employed increases, but labour market turnover also coincidentally increases. Notably, the results on overall time spent employed are driven primarily by the drop in unemployment duration caused by shorter UIS benefit periods. For example, when the entitlement duration drops by $50 \%$, overall time spent employed increases by $0.67,2.33$ and $2.58 \%$ for young, middle-age and older workers, respectively. Mean unemployment duration drops by approximately 5, 37 and $42 \%$, respectively, and mean employment duration decreases by approximately $0.57,3$ and $6 \%$, respectively. Thus, in this context, job turnover also increases. The number of unemployment spells increases by $1.4,3.2$ and $2.5 \%$ for the respective age groups, whereas the number of job spells increases by 1.6, 4.6 and $3.5 \%$, respectively. Interestingly, when we dig deeper and look at the 25 th and 75 th percentiles, we observe that this gain in employment stability occurs primarily for low-stability workers. For these workers (those located below the 25 th percentile), employment stability increases by $2.86,4.76$ and $6.82 \%$ for the respective age groups. Again, this increase in employment stability is driven primarily by a decrease in unemployment duration.

When we look at the alternative policy regime, in which the duration of benefits doubles, the results are basically similar although, of course, with opposite sign. Note that the decrease in benefit duration does not translate into significant gains in stability (the percentage of workers ending the simulated 60 months with a permanent contract

\footnotetext{
35 We also perform the simulation for a 10-year period. Given that the results do not change qualitatively, we have opted to omit these data, although they are available upon request.

36 The results for the rest of the workers are quite similar to the ones shown here, although they are much lower in absolute value.
} 
Table 15 Main simulation results: effect of changing the UIS entitlement length (sub-sample: those beginning working under a temporary contract, low and medium skill workers)

\begin{tabular}{|c|c|c|c|c|c|c|c|c|}
\hline & \multicolumn{4}{|l|}{ Mean } & \multicolumn{4}{|l|}{ P25 } \\
\hline & $\begin{array}{l}\text { Status } \\
\text { quo }\end{array}$ & $\begin{array}{l}\text { Drop } \\
50 \%\end{array}$ & $\begin{array}{l}\text { Increase } \\
50 \%\end{array}$ & $\begin{array}{l}\text { Increase in } \\
\text { PC offers }\end{array}$ & $\begin{array}{l}\text { Status } \\
\text { quo }\end{array}$ & $\begin{array}{l}\text { Drop } \\
50 \%\end{array}$ & $\begin{array}{l}\text { Increase } \\
50 \%\end{array}$ & $\begin{array}{l}\text { Increase in } \\
\text { PC offers }\end{array}$ \\
\hline \multicolumn{9}{|l|}{ Aged $<30$} \\
\hline No. of employment spells & 5.55 & 5.62 & 5.49 & 4.06 & 3 & 3 & 3 & 2 \\
\hline No. of unemployment spells & 2.89 & 2.94 & 2.88 & 1.88 & 1 & 1 & 1 & 1 \\
\hline Mean employment duration & 11.54 & 11.48 & 11.52 & 15.60 & 5.11 & 5.11 & 5.13 & 8.33 \\
\hline Mean unemployment duration & 5.80 & 5.51 & 6.13 & 6.18 & 2.5 & 2.33 & 2.80 & 2 \\
\hline Total months employed & 44.79 & 45.09 & 44.32 & 48.93 & 35 & 36 & 35 & 36 \\
\hline$\%$ Workers ending into a PC & 47.57 & 47.72 & 46.92 & 79.64 & - & - & - & - \\
\hline UI individual balance & 1.47 & 1.99 & 1.18 & 2.47 & -0.38 & 0.59 & -0.87 & 1.06 \\
\hline \multicolumn{9}{|l|}{ Aged $30-45$} \\
\hline No. of employment spells & 5.58 & 5.76 & 5.44 & 3.83 & 3 & 3 & 3 & 2 \\
\hline No. of unemployment spells & 2.88 & 3.01 & 2.81 & 1.71 & 1 & 1 & 1 & 1 \\
\hline Mean employment duration & 12.87 & 12.83 & 12.84 & 17.50 & 6.11 & 6.11 & 6.0 & 10.0 \\
\hline Mean unemployment duration & 4.84 & 3.92 & 5.47 & 5.41 & 2.33 & 2.0 & 2.66 & 2.0 \\
\hline Total months employed & 48.36 & 49.49 & 47.39 & 51.80 & 42 & 44 & 40 & 47 \\
\hline$\%$ Workers ending into a PC & 36.82 & 37.47 & 36.42 & 77.59 & - & - & - & - \\
\hline UI individual balance & 0.270 & 0.717 & -0.0368 & 1.299 & -1.96 & -1.21 & -2.43 & -0.46 \\
\hline \multicolumn{9}{|l|}{ Aged $>45$} \\
\hline No. of employment spells & 4.67 & 4.79 & 4.55 & 3.43 & 3 & 3 & 3 & 2 \\
\hline No. of unemployment spells & 2.11 & 2.18 & 2.03 & 1.33 & 1 & 1 & 1 & 1 \\
\hline Mean employment duration & 16.45 & 16.56 & 16.51 & 20.25 & 7.60 & 7.71 & 7.60 & 11.50 \\
\hline Mean unemployment duration & 5.47 & 4.35 & 6.21 & 6.23 & 2.5 & 2.0 & 2.83 & 2.75 \\
\hline Total months employed & 50.42 & 51.72 & 49.77 & 52.78 & 44 & 47 & 43 & 49 \\
\hline$\%$ Workers ending into a PC & 34.27 & 35.57 & 34.27 & 71.29 & - & - & - & - \\
\hline \multirow[t]{3}{*}{ UI individual balance } & 0.883 & 1.303 & 0.724 & 1.647 & -1.28 & -0.71 & -1.46 & -0.29 \\
\hline & \multicolumn{8}{|l|}{ P75 } \\
\hline & $\begin{array}{l}\text { Status } \\
\text { quo }\end{array}$ & $\begin{array}{l}\text { Drop } \\
50 \%\end{array}$ & $\begin{array}{l}\text { Increase } \\
50 \%\end{array}$ & \multicolumn{5}{|c|}{ Increase in PC offers } \\
\hline \multicolumn{9}{|l|}{ Aged $<30$} \\
\hline No. of employment spells & 7 & 7 & 7 & 5 & & & & \\
\hline No. of unemployment spells & 4 & 4 & 4 & 3 & & & & \\
\hline Mean employment duration & 15.0 & 14.75 & 15.0 & 20.0 & & & & \\
\hline Mean unemployment duration & 7.2 & 7 & 7.75 & 8 & & & & \\
\hline Total months employed & 57 & 57 & 57 & 58 & & & & \\
\hline$\%$ Workers ending into a PC & -- & -- & -- & - & & & & \\
\hline UI individual balance & 4.56 & 4.56 & 4.56 & 4.81 & & & & \\
\hline \multicolumn{9}{|l|}{ Aged $30-45$} \\
\hline No. of employment spells & 7 & 7 & 7 & 5 & & & & \\
\hline No. of unemployment spells & 4 & 4 & 4 & 2 & & & & \\
\hline
\end{tabular}


Table 15 continued

\begin{tabular}{lllll}
\hline & P75 & & & \\
\cline { 2 - 5 } & $\begin{array}{l}\text { Status } \\
\text { quo }\end{array}$ & $\begin{array}{l}\text { Drop } \\
50 \%\end{array}$ & $\begin{array}{l}\text { Increase } \\
50 \%\end{array}$ & Increase in PC offers \\
\hline Mean employment duration & 17.0 & 16.67 & 16.67 & 24.0 \\
Mean unemployment duration & 6.0 & 5.0 & 7.0 & 7.0 \\
Total months employed & 57 & 57 & 57 & 59 \\
\% Workers ending into a PC & - & - & - & - \\
UI individual balance & 3.41 & 3.41 & 3.33 & 4.19 \\
Aged $>$ 45 & & & & 4 \\
No. of employment spells & 6 & 6 & 6 & 2 \\
No. of unemployment spells & 3 & 3 & 3 & 28.00 \\
Mean employment duration & 20.00 & 20.00 & 20.00 & 8.33 \\
Mean unemployment duration & 7 & 5.4 & 8 & 60 \\
Total months employed & 59 & 59 & 59 & - \\
\% Workers ending into a PC & - & - & - & 4.98 \\
UI individual balance & 4.81 & 4.81 & 4.81 & \\
\hline
\end{tabular}

is only slightly larger) but, as would be expected, the gains in terms of UIS individual balance are much more important (when UI entitlements drop by $50 \%$, the individual balance of the system grows by $35.4 \%$ ).

In any case, neither of the two alternative benefit regimes seems to cause a significant variation in employment stability. However, the results are significantly different for the final simulation, in which the gap between the probability of exiting to a permanent contract and the probability of exiting to a temporary contract, from either employment or unemployment, is decreased by $20 \%$. The large increase in employment stability and the decrease in job turnover induced by the increase in the probability of entering into a permanent contract are both notable. In this case, job stability increases by $10 \%$ for young and middle-age workers and by $7 \%$ for older workers. This increase in job stability is primarily related to lengthier employment spells and, to a lesser extent, to shorter unemployment episodes. In particular, mean employment duration increases by 35,36 and $23 \%$ for young, middle-age and older workers, respectively. It is also notable that the growth in the share of workers that obtain permanent contracts increases from 47 to $79 \%$, from 36 to $77 \%$ and from 34 to $71 \%$, respectively, for each age group.

\section{Summary and conclusions}

Changes in the UIS design happen quite frequently in a response to changing economic conditions or based on dissatisfaction with the previous design. However, the extent to which workers' careers might improve or deteriorate as a result of changes in the unemployment insurance design is not immediately clear. One might want to 
understand the impact of observed changes to the unemployment insurance system on workers' careers over time. In this paper, we have attempted to go a step further than previous empirical analyses and offer an assessment of the overall influence of UIS entitlement duration on employment stability, simultaneously accounting for the competing effects of benefits on the duration of both unemployment and employment and also considering the occurrence of state dependence. In addition, we take advantage of the Spanish labour market because it allows an assessment of whether the effects of benefit entitlement differ between stable and unstable labour market workers.

We find evidence of a positive effect of benefits on subsequent job duration, especially for temporary workers, through two main channels. First, insured workers have lengthier subsequent job spells than uninsured workers, and this effect becomes more significant as the length of the entitlement period increases. Second, previously insured workers holding temporary contracts might experience greater probabilities of transition to permanent contracts than uninsured workers. Hence, previously insured workers might benefit from better employment prospects than uninsured workers, either by remaining in the same job or moving directly to a new permanent job. We illustrate our results by simulating the processes of finding and losing work, starting with an initial spell of employment and spanning the sample frame for each individual in the data. These simulations are used to predict the effects of policy changes on the group of workers in our sample. The main conclusion drawn from this simulation exercise is that a reduction in the duration of unemployment benefits seems to have little effect on time spent employed, whereas it increases job turnover rates. On the contrary, when we simulate an increase in the entrance probability to a permanent contract, positive and long-lasting effects are found in terms of job stability. In this last case, job stability increases by $10 \%$ for young and middle-age workers and by $7 \%$ for older workers.

These results may be important from a policy perspective. It is interesting to attempt to analyse the trade-offs in terms of social welfare between the costs of having shorter employment spells or a more generous UI benefit system (a discussion re-examined in Marimon and Zilibotti 1999). In particular, for a segmented labour market such as the one in Spain, it is interesting to account for the ability of the UIS to foster or limit the negative effect of job turnover, which opens up new perspectives on the UIS system. Furthermore, given the current debate about the optimal design of unemployment benefits over the business cycle (see, for example, Schmieder et al. 2012; Landais 2013 or Hagedorn et al. 2013), it could be very interesting to analyse whether unemployment benefits in Spain should increase or decrease during bad times. Note that as Chetty (2008), we have found evidence that not only moral hazard effects but also liquidity constraints could explain the strong correlation between benefit entitlement and unemployment duration. However, to account for the effects put forward in Schmieder et al. (2012), Landais (2013) or Hagedorn et al. (2013) the present reduced-form model should be properly modified in order to separately identify the effects of such benefits on workers behaviour and the ones on firms' decision about vacancies. Hence, it would be only with data on firms' decisions that the micro and macro effects of unemployment benefits could be properly analysed. This is part of our future research agenda. 
Acknowledgments We are grateful to Bart Cockx, Konstantinos Tatsiramos, Samuel Bentolila and seminar participants at EALE 2012, ESPE 2013, and the Symposium of Economic Analysis for comments on previous versions of the paper. All remaining errors are our own. This project has benefited from the financial support of the Spanish Ministry of Education (projects ECO2010-21706 and ECO2013-43526-R).

Open Access This article is distributed under the terms of the Creative Commons Attribution License which permits any use, distribution, and reproduction in any medium, provided the original author(s) and the source are credited.

\section{Appendix A: Table of results}

See Tables 16, 17, and 18 . 
Table 16 Estimation results for the employment state (other covariates)

\begin{tabular}{|c|c|c|c|c|c|c|c|c|}
\hline \multirow[t]{2}{*}{ Competing risks } & \multicolumn{2}{|l|}{ Layoff } & \multicolumn{2}{|l|}{ Quit } & \multicolumn{2}{|l|}{$\mathrm{JJ}-\mathrm{PC}$} & \multicolumn{2}{|l|}{$\mathrm{JJ}-\mathrm{TC}$} \\
\hline & Coeff. & z-stat & Coeff. & z-stat & Coeff. & z-stat & Coeff. & z-stat \\
\hline \multicolumn{9}{|l|}{ Individual characteristics } \\
\hline Age & -0.1609 & -34.52 & -0.5524 & -42.4 & -0.1416 & -15.86 & -0.1139 & -17.25 \\
\hline Inmigrant & 0.0460 & 4.91 & 0.5127 & 28.24 & -0.0104 & -0.66 & 0.4129 & 26.71 \\
\hline Seniority & -0.0742 & -42.68 & -0.0797 & -21.29 & 0.0593 & 14.71 & 0.0355 & 12.47 \\
\hline First job spell & -0.6613 & -28.86 & -0.1799 & -4.32 & 0.4914 & 9.42 & 0.1500 & 4.59 \\
\hline \multicolumn{9}{|l|}{ Job characteristics } \\
\hline Part-time & 0.2148 & 23.25 & 0.5400 & 33.24 & 0.0274 & 1.39 & 0.3883 & 30.74 \\
\hline High skill job & -0.3589 & -36.25 & -0.5096 & -26.75 & 0.1193 & 7.95 & -0.4590 & -31.97 \\
\hline Construction & -0.2464 & -23.43 & -0.2887 & -16.46 & -0.8524 & -43.33 & -0.0953 & -1.21 \\
\hline Industry & -0.1612 & -18.21 & -0.5253 & -25.32 & -0.3126 & -20.99 & -0.3666 & -21.2 \\
\hline Small firm $(<20)$ & 0.044 & 7.59 & 0.1243 & 9.08 & 0.1032 & 6.7 & 0.1406 & 11.8 \\
\hline Public firm & 0.1491 & 12.35 & -1.3662 & -26.22 & -0.9641 & -28.67 & -0.3920 & -14.01 \\
\hline Temporary help agency & 0.6657 & 54.87 & 0.0914 & 2.04 & 1.0772 & 37.71 & 1.2036 & 62.89 \\
\hline $\mathrm{PC}$ & -2.3654 & -59.85 & -1.3432 & -27.58 & -1.2256 & -22.9 & -2.9181 & -49.82 \\
\hline \multicolumn{9}{|l|}{ Aggregate variables } \\
\hline Regional unemployment rate & 0.0374 & 5.31 & -0.3891 & -25.76 & -0.2917 & -23.11 & -0.0377 & -4.74 \\
\hline National GDP growth rate & -0.0542 & -3.6 & 0.0177 & 0.6 & 0.3163 & 12.29 & 0.1088 & 5.41 \\
\hline \multicolumn{9}{|l|}{ Duration dependence (logs) } \\
\hline Duration*TC & -0.3476 & -15.11 & 0.3987 & 6.44 & 0.4333 & 3.93 & -0.4107 & -14.14 \\
\hline Duration $^{2} * \mathrm{TC}$ & 0.1798 & 10.27 & -0.5332 & -6.07 & -0.4661 & -4.31 & 0.2206 & 11.87 \\
\hline Duration $^{3} * \mathrm{TC}$ & -0.0532 & -16.16 & 0.1839 & 4.51 & 0.2464 & 6.39 & -0.0508 & -14.94 \\
\hline Duration $^{4 * \mathrm{TC}}$ & - & - & -0.0251 & -4.47 & -0.0323 & -8.66 & - & - \\
\hline Duration*PC & -1.2724 & -14.47 & -0.7776 & -9.17 & -0.9544 & -10.67 & 0.7027 & 15.53 \\
\hline Duration $^{2} * \mathrm{PC}$ & 0.8092 & 22.29 & 0.5443 & 11.4 & 0.7500 & 17.7 & -0.2073 & -23.04 \\
\hline Duration $^{3 *} \mathrm{PC}$ & -0.1379 & -26.49 & -0.1069 & -14.54 & -0.1371 & -23.13 & - & - \\
\hline$($ Duration $=3) * \mathrm{TC}$ & 0.3983 & 35.98 & - & - & 0.3515 & 12.12 & 0.1930 & 14.94 \\
\hline$($ Duration $=6) * \mathrm{TC}$ & 0.9377 & 77.42 & - & - & 1.2261 & 50.2 & 0.8674 & 63.61 \\
\hline$($ Duration $=9) * \mathrm{TC}$ & 0.4651 & 22.08 & - & - & 0.4614 & 12.57 & 0.3633 & 17.56 \\
\hline$($ Duration $=12) * \mathrm{TC}$ & 1.3415 & 73.04 & - & - & 1.6721 & 61.36 & 1.4198 & 74.75 \\
\hline$($ Duration $=24) * \mathrm{TC}$ & 0.9907 & 23.55 & - & - & 1.4484 & 33.33 & 0.9692 & 10.11 \\
\hline$($ Duration $=36) * \mathrm{TC}$ & 0.8272 & 10.65 & - & - & 0.8454 & 10.81 & 0.9013 & 11.72 \\
\hline$($ Duration $=6) * \mathrm{PC}$ & 0.3306 & 6.47 & - & - & 0.3817 & 2.71 & -0.1575 & -2.85 \\
\hline$($ Duration $=12) * \mathrm{PC}$ & 0.3721 & 6.65 & - & - & 0.0834 & 2.32 & - & - \\
\hline$($ Duration $=24) * \mathrm{PC}$ & 0.2789 & 4.31 & - & - & 0.2844 & 3.42 & - & - \\
\hline \multicolumn{9}{|l|}{ Previous state characteristics } \\
\hline Job-to-job & -0.4843 & -45.800 & -0.2631 & -11.38 & 0.0565 & 3.34 & 0.0428 & 3.8 \\
\hline Unemployed due to a quit & -0.1746 & -13.010 & 0.2752 & 14.36 & 0.1150 & 5.98 & 0.0184 & 1.50 \\
\hline Received assistant benefits & 0.1246 & 6.13 & -0.3536 & -4.89 & -0.0003 & 0.56 & -0.0238 & -0.82 \\
\hline Constant & -2.0630 & -104.4 & -2.0525 & -51.56 & -3.8664 & -100.23 & -3.3741 & -114.4 \\
\hline
\end{tabular}

$T C$ temporary contract, $P C$ permanent contract 
Table 17 Estimation results for the unemployment state (other covariates)

\begin{tabular}{|c|c|c|c|c|}
\hline \multirow[t]{2}{*}{ Competing risks } & \multicolumn{2}{|l|}{ TC } & \multicolumn{2}{|l|}{$\mathrm{PC}$} \\
\hline & Coeff & z-stat & Coeff & z-stat \\
\hline \multicolumn{5}{|l|}{ Individual characteristics } \\
\hline Age & -0.0840 & -16.91 & -0.0549 & -1.76 \\
\hline Inmigrant & 0.4152 & 31.1 & -0.1015 & -1.47 \\
\hline Seniority & 0.2567 & 61.56 & 0.4934 & 20.73 \\
\hline \multicolumn{5}{|l|}{ Job characteristics } \\
\hline Part-time & -0.1583 & -15.41 & 0.1051 & 2.19 \\
\hline High skill job & -0.0170 & -2.18 & 0.2785 & 6.18 \\
\hline Construction & 0.1413 & 14.65 & -0.6891 & -9.71 \\
\hline Industry & 0.0387 & 5.38 & 0.0793 & 1.45 \\
\hline Small firm $(<20)$ & -0.0061 & -0.35 & -0.0600 & -1.49 \\
\hline Public firm & -0.2081 & -12.85 & -0.5460 & -6.29 \\
\hline Temporary help agency & 0.2142 & 16.32 & -0.0248 & -0.25 \\
\hline $\mathrm{PC}$ & -0.0168 & -1.03 & 0.1173 & 1.27 \\
\hline \multicolumn{5}{|l|}{ Aggregate variables } \\
\hline Regional unemployment rate & -0.0211 & -3.78 & -0.1264 & -3.15 \\
\hline National GDP growth rate & 0.0981 & 6.56 & 0.3785 & 2.10 \\
\hline \multicolumn{5}{|l|}{ Duration dependence (logs) } \\
\hline $\log ($ duration $) * \mathrm{TC}$ & -0.7105 & -15.62 & -0.8284 & -12.07 \\
\hline $\log (\text { duration })^{2 * \mathrm{TC}}$ & 0.6795 & 8.3 & 0.2453 & 10.27 \\
\hline $\log (\text { duration })^{3 * \mathrm{TC}}$ & -0.4031 & -9.75 & - & - \\
\hline $\log (\text { duration })^{4 * \mathrm{TC}}$ & 0.0772 & 12.32 & - & - \\
\hline $\log ($ duration $) * \mathrm{PC}$ & -0.8551 & -7.24 & -0.2884 & -2.26 \\
\hline $\log (\text { duration })^{2} * \mathrm{PC}$ & 0.8324 & 3.98 & 0.0426 & 0.97 \\
\hline $\log (\text { duration })^{3} * \mathrm{PC}$ & -0.4923 & -4.85 & - & - \\
\hline $\log (\text { duration })^{4 * P C}$ & 0.0906 & 6.08 & - & - \\
\hline$($ Duration $=6) * \mathrm{TC}$ & 0.0414 & 1.73 & - & - \\
\hline (Duration $=12$ ) $* \mathrm{TC}$ & 0.5513 & 26.99 & - & - \\
\hline$($ Duration $=12) * \mathrm{PC}$ & 0.0727 & 1.27 & - & - \\
\hline \multicolumn{5}{|l|}{ UIS variables } \\
\hline Receives assistant benefits & -0.8316 & -39.72 & -1.2888 & -9.53 \\
\hline Unemployed due to a quit & -0.0948 & -10.51 & 0.0384 & -0.47 \\
\hline Constant & -1.7278 & -62.44 & -6.8789 & -43.6 \\
\hline
\end{tabular}


Table 18 Estimation results for the individual heterogeneity distribution

\begin{tabular}{lllll}
\hline & \multicolumn{4}{l}{ Individual heterogeneity distribution $(\mathrm{M}=3)$} \\
\cline { 2 - 5 } & Coef & Z-stat & Coef & Z-stat \\
\hline Points of support & Type I & & Type II & \\
Employment & & & & \\
$\quad$ Layoff & -0.8954 & -62.12 & -0.9944 & -47.63 \\
$\quad$ Quit & -1.1249 & -40.77 & -1.248 & -39.9 \\
$\quad$ JJ-PC & -0.7852 & -27.91 & -1.1298 & -40.98 \\
$\quad$ JJ-TC & -0.6599 & -26.2 & -1.569 & -71.18 \\
Unemployment & & & & \\
$\quad$ TC & 0.6342 & 32.97 & -0.1945 & -8.42 \\
$\quad$ PC & 2.5694 & 19.47 & 0.5564 & 3.7 \\
Probability masses (logistic transformation) & 0.5787 & 12.45 & 1.006 & 21.43 \\
Resulting probabilities & $32.31 \%$ & & $49.56 \%$ & \\
\hline
\end{tabular}

\section{Appendix B: Goodness of fit}

To check how well the model fits the main characteristics of the data, no simple test is available. Rather, employment histories have to be simulated and then compared to the original data. For that purpose, our full sample is divided into two subsamples, one used for estimation purposes the other used for simulation purposes. That is, for a given sample of individuals (50\% of the individuals), we conduct the simulations dynamically from the beginning of their first spell in the sample until the end of their fifth year in the labour force. Thus, we simulate their first sixty months in their labour market career. The steps followed in the simulation are now described.

For these simulations, the exogenous variables are taken from the observed data (i.e. the characteristics of the first spell are given by the original data), whereas the endogenous ones are constructed by using the parameters estimated using the other $50 \%$ of the individuals in the sample. In the first spell, we randomly assign each individual in the sample a value of the individual unobserved heterogeneity coefficient (i.e. we determine of which type the individual is). This assignment of "individual types" is driven by the estimated distribution of unobserved heterogeneity. The second step is to assign to each individual their transition intensities and destination states. Given the set of exogenous explanatory variables, the individual random effect and the endogenous variables, we compute the hazard rates for each individual. The destination states in the following period are determined by the estimated hazard rates and by an exogenous shock. Whenever the hazard exceeds the exogenous shock, a transition into another state takes place and we start evaluating the hazards out of the new state, conditional on the individual's labour market history. After a transition has taken place, the record of the individual is updated to reflect changes in employment history and in the UIS parameters. This process is repeated until each worker is simulated over 


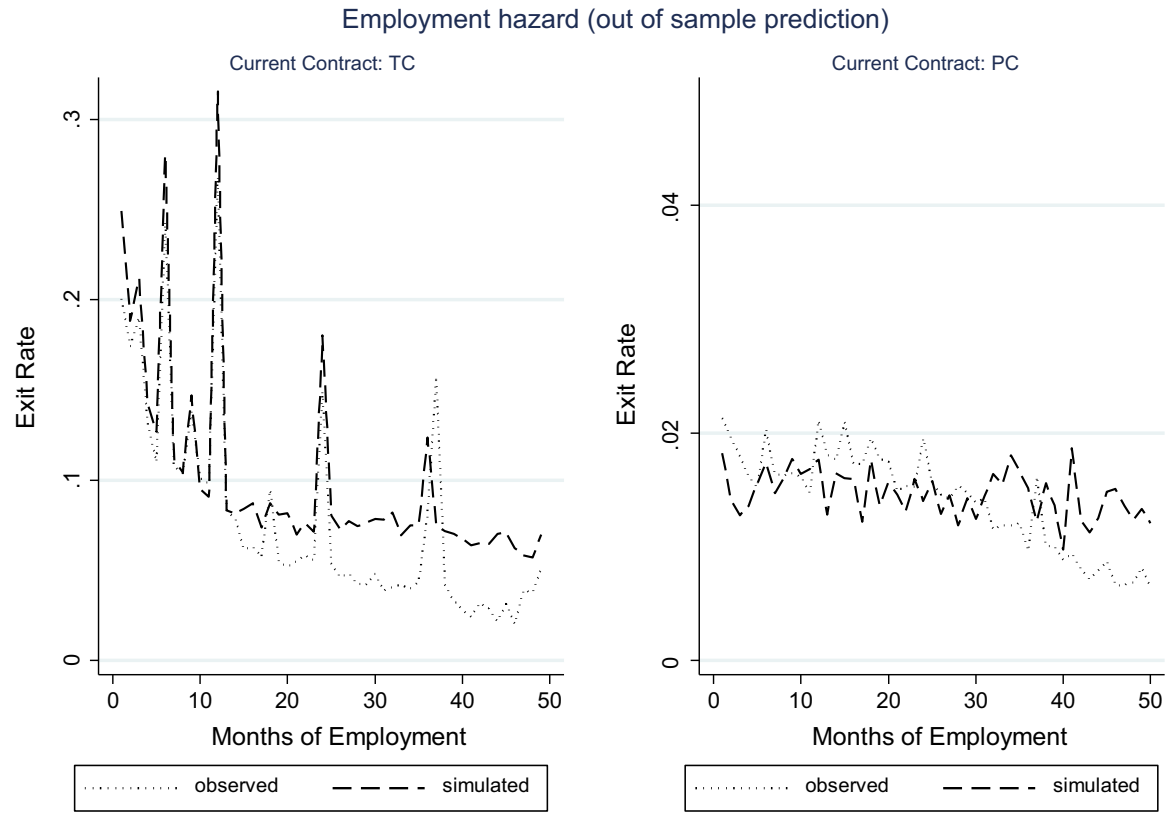

Fig. 6 Goodness of fit for the Employment Hazard Notice that temporary contracts with duration lengthier than 36 months are not common given the regulation of temporary contracts in Spain. Those cases correspond with workers who remained in the same firm with different temporary contracts but had job interruptions shorter than 15 days

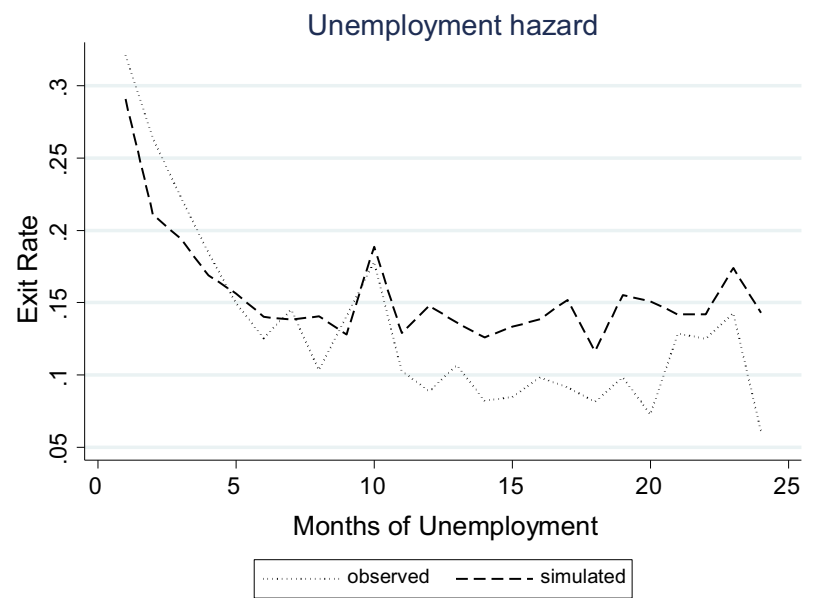

Fig. 7 Goodness of fit for the unemployment hazard

the periods which are observed. The resulting data set is a random history, which is compatible with the exogenous and endogenous variables.

The simulation results we present are averaged over the distribution of unobserved heterogeneity. The result of this exercise is then compared to the raw data used to 
Table 19 Goodness of fit

\begin{tabular}{lll}
\hline & Raw data & Simulated data \\
\hline $\begin{array}{l}\text { Mean employment duration } \\
\text { (current contract: TC) }\end{array}$ & 4.47 & 5.46 \\
$\begin{array}{l}\text { Mean employment duration } \\
\text { (current contract: PC) } \\
\begin{array}{l}\text { Mean unemployment } \\
\text { duration }\end{array}\end{array}$ & 30.65 & 32.97 \\
$\begin{array}{l}\text { Time spent employed } \\
\text { Mime }\end{array}$ & 5.02 & 4.75 \\
\end{tabular}

execute the simulation. Figures 6 and 7 compare empirical hazard rates to simulated hazard rates and Table 19 presents main summary statistics for both the simulated data and the raw data. These statistics are mean employment and unemployment duration as well as time spent employed during the simulated period. As can be seen from these figures and table the model fits the data relatively well.

\section{References}

Abbring JH, van den Berg GJ (2004) Analysing the effect of dynamically assigned treatments using duration models, binary treatment models, and panel data models. Empirical Econ 29:5-40

Acemoglu D, Shimer R (2000) Productivity gains from unemployment insurance. Eur Econ Rev 44(7):11951224

Alba-Ramirez A, Arranz JM, Muñoz-Bullón F (2007) Exits from unemployment: recall or new job. Labour Econ 14:788-810

Arranz JM, Muro J (2004) An extra time duration model with application to unemployment duration under benefits in Spain. Hacienda Pública Española, IEF, vol 171(4), pp 133-156

Belzil C (2001) Unemployment insurance and subsequent job duration: job matching versus unobserved heterogeneity. J Appl Econ 16(5):619-636

Bentolila S, Cahuc P, Dolado D, Le Barbanchon T (2010) Unemployment and temporary jobs in the crisis: comparing France and Spain, Working Papers 2010-07, FEDEA

Blanchard O, Jaumotte F, Loungani P (2013) Labor market policies and IMF advice in advanced economies during the great recession, IMF Staff Discussion Note 13/02

Boone J, Van Ours JC (2009) Why is there a spike in the job finding rate at benefit exhaustion? CEPR Discussion Papers 7525

Boone JF, Abdolkarim S, Van Ours JC (2009) Experiment on unemployment benefit sanctions and job search behaviour. Eur Econ Rev 53(8):937-951

Booth AL, Francesconi M, Frank J (2002) Temporary jobs: stepping stones or dead ends? Econ J 112:F189_ F213

Bover O, Arellano M, Bentolila S (2002) Unemployment duration, benefit duration and the business cycle. Econ J 112:223-265

Brinch C (2000) Identification of structural duration dependence and unobserved heterogeneity with timevarying covariates, Memorandum 20/2000, Oslo University, Department of Economics

Caliendo M, Tatsiramos K, Uhlendorff A (2009) Benefit duration, unemployment duration and job match quality: a regression-discontinuity approach, IZA Discussion Papers 4670

Caliendo M, Künn S, Uhlendorff A (2012) Marginal employment, unemployment duration and job match quality. IZA discussion papers 6499, Institute for the Study of Labor (IZA)

Card, Levine (2000) Extended benefits and the duration of UI spells: evidence from the New Yersey extended benefit program. J Publ Econ 78:107-138

Card D, Chetty R, Weber A (2007) The spike at benefit exhaustion: leaving the unemployment system or starting a new job? Am Econ Rev 97:113-118 
Centeno M (2004) The match quality gains from unemployment insurance. J Hum Resour 39(3)

Chetty R (2008) Erratum: Moral hazard versus liquidity and optimal unemployment insurance. J Polit Econ Univ Chicago Press 116(6):1197-1197

Duran A (2007) La Muestra Continua de Vidas Laborales de la Seguridad Social, Revista del Ministerio de Trabajo y Asuntos Sociales, No 1, pp 231-240

Eberwein C, John C, LaLonde RJ (2002) Alternative methods of estimating program effects in event history models. Labour Econ 9(2):249-278

García Pérez JI (2008) La Muestra Continua de Vidas laborales (MCVL): una guía de uso para el análisis de transiciones laborales. Revista de Economía Aplicada, XVI(E-I), pp 5-28

Gaure S, Roed Kr (2007) Time and causality: a Monte Carlo assessment of the timing-of-events approach. J Econ 141:1159-1195

Güell M, Petrongolo B (2007) How binding are legal limits? Transitions from temporary to permanent work in Spain. Labour Econ 14:153-183

Hagedorn M, Karahan F, Manovskii I, Mitman K (2013) Unemployment Benefits and Unemployment in the Great Recession: the role of macro effects, NBER Working Paper No. 19499

Heckman JJ, Singer B (1984) The identifiability of the proportional hazard model. Rev Econ Studies 51:231-241

Jenkins S (1995) Easy estimation methods for discrete time duration models. Oxf Bull Econ Stat 57(1):129_ 137

Jovanovic B (1979) Job matching and the theory of turnover. J Polit Econ 87(5):972-990

Krause MU, Uhlig H (2012) Transitions in the German labor market: structure and crisis. J Monetary Econ Elsevier 59(1):64-79

Krebs T, Scheffel M (2013) Macroeconomic evaluation of labor market reform in Germany. IMF Econ Rev Palgrave Macmillan 61(4):664-701

Lalive R (2007) Unemployment benefits, unemployment duration, and post-unemployment jobs: a regression discontinuity approach. Am Econ Rev 91(2):108-112

Landais C, Michaillat P, Saez E (2013) Optimal unemployment insurance over the business cycle. National Bureau of Economic Research Working Paper No. 16526

Launov A, Wälde K (2013) Estimating incentive and welfare effects of nonstationary unemployment benefits. Int Econ Rev 54:1159-1198

Marimon R, Zilibotti F (1999) Unemployment vs. mismatch of talents: reconsidering unemployment benefits. Econ J 109(455):266-291

Meyer BD (1990) Unemployment insurance and unemployment spells. Econometrica 58(4):757-782

OECD (2013) OECD Employment Outlook 2013. OECD Publishing, Paris

Rebollo-Sanz YF (2011) Landing a permanent contract in Spain: do job interruptions and employer diversification matter? The Manchester School 79:1197-1236

Rebollo-Sanz YF (2012) Unemployment insurance and job turnover in Spain. Labour Econ, No. 10-08

Roed K, Zhang T (2003) Does unemployment compensation affect unemployment duration? Econ J 113:119

Schmieder JF, Von Wachter TM, Bender S (2012) The effects of extended unemployment insurance over the bussines cycle: evidence from regression discontinuity estimates over twenty years NBER Working Paper No. 17813

Silva JI, Vázquez-Grenno J (2013) The ins and outs of unemployment in a two-tier labor market. Labour Econ 24(C):161-169

Tatsiramos K (2009) Unemployment insurance in Europe: unemployment duration and subsequent employment stability. J Eur Econ Assoc MIT Press 7(6):1225-1260

Tatsiramos K, Van Ours JC (2012) Labour market effects of unemployment insurance design, CEPR Discussion Papers 9196. C.E.P.R, Discussion Papers

Van Ours JC, Vodopivec M (2008) Does reducing unemployment insurance generosity reduce job match quality? J Public Econ Elsevier 92(3-4):684-695

Van Ours J, Vodopivec M (2006) Shortening the potential duration of unemployment benefits does not affect the quality of post-unemployment jobs: evidence from a natural experiment, IZA discussion paper 2171 